\title{
1 Field data confirm the ability of a biophysical model to predict wild primate body
}

\section{2 temperature}

4 Paul D. Mathewson ${ }^{\mathrm{a}}$, Warren P. Porter ${ }^{\mathrm{a}}$, Louise Barrett ${ }^{\mathrm{b}, \mathrm{c}}$, Andrea Fuller ${ }^{\mathrm{c}}$, S. Peter Henzi ${ }^{\mathrm{b}, \mathrm{c}}$,

5 Robyn S. Hetem ${ }^{\mathrm{c}, \mathrm{d}}$, Christopher Young ${ }^{\mathrm{b}, \mathrm{e}, \mathrm{f}}$, Richard McFarland ${ }^{\mathrm{a}, \mathrm{c}, \mathrm{g}}$

6

$7 \quad{ }^{a}$ Department of Integrative Biology, University of Wisconsin-Madison, USA.

$8 \quad{ }^{b}$ Department of Psychology, University of Lethbridge, Canada

$9 \quad{ }^{\mathrm{c}}$ Brain Function Research Group, School of Physiology, Faculty of Health Science, University

10 of the Witwatersrand, South Africa.

11 d School of Animal, Plant and Environmental Sciences, Faculty of Science, University of the

12 Witwatersrand, South Africa.

$13{ }^{\mathrm{e}}$ Applied Behavioural Ecology \& Ecosystems Research Unit, University of South Africa, South 14 Africa

$15{ }^{\mathrm{f}}$ Endocrine Research Laboratory, Mammal Research Institute, Faculty of Natural and

16 Agricultural Science, University of Pretoria, Pretoria, South Africa

$17{ }^{\mathrm{g}}$ Department of Anthropology, University of Wisconsin-Madison, USA.

19 Corresponding Author: Paul D. Mathewson

Department of Integrative Biology, University of Wisconsin, Madison 250 North Mills Street, Madison, WI 53706 


\section{ABSTRACT}

25 In the face of climate change there is an urgent need to understand how animal performance is

26 affected by environmental conditions. Biophysical models that use principles of heat and mass

27 transfer can be used to explore how an animal's morphology, physiology, and behavior interact

28 with its environment in terms of energy, mass and water balances to affect fitness and

29 performance. We used Niche Mapper ${ }^{\mathrm{TM}}$ (NM) to build a vervet monkey (Chlorocebus

30 pygerythrus) biophysical model and tested the model's ability to predict core body temperature

$31\left(\mathrm{~T}_{b}\right)$ variation and thermal stress against $\mathrm{T}_{\mathrm{b}}$ and behavioral data collected from wild vervets in

32 South Africa. The mean observed $\mathrm{T}_{\mathrm{b}}$ in both males and females was within $0.5^{\circ} \mathrm{C}$ of NM's

33 predicted $\mathrm{T}_{b} \mathrm{~s}$ for $91 \%$ of hours over the five-year study period. This is the first time that NM's

$34 \mathrm{~T}_{\mathrm{b}}$ predictions have been validated against field data from a wild endotherm. Overall, these

35 results provide confidence that NM can accurately predict thermal stress and can be used to

36 provide insight into the thermoregulatory consequences of morphological (e.g., body size, shape,

37 fur depth), physiological (e.g. Tb plasticity) and behavioral (e.g., huddling, resting, shade

38 seeking) adaptations. Such an approach allows users to test hypotheses about how animals adapt

39 to thermoregulatory challenges and make informed predictions about potential responses to

40 environmental change such as climate change or habitat conversion. Importantly, NM's animal

41 submodel is a general model that can be adapted to other species, requiring only basic

42 information on an animal's morphology, physiology and behavior.

43

44 KEY WORDS

45 Chlorocebus pygerythrus; ecological energetics; endotherm; metabolic rate; Niche Mapper;

46 thermoregulation; vervet monkey 


\section{1. INTRODUCTION}

48 Given the threat that global climate change poses to biodiversity (Pacifici et al. 2015, Urban et

49 al. 2016) there is a pressing need to understand the fitness consequences of environmental

50 changes from a physiological perspective (Fuller 2010). Endotherms employ a range of

51 adaptations to cope with environmental challenges, and when unable to maintain their optimal

52 body temperature range, animals can experience reduced cellular efficiency and fitness

53 (Seebacher and Little 2017, Maloney et al. 2017). Homeothermy - maintaining a body

54 temperature within a relatively narrow range despite environmental temperature variation - is

55 achieved through a combination of physiological (autonomic) and behavioral processes.

56 Physiological processes can be costly in terms of energy expenditure through increased

57 metabolic heat production and water loss through evaporative cooling (Fuller et al. 2016,

58 Levesque et al. 2016). To reduce the physiological costs of thermoregulation, individuals can

59 also engage in behaviors that influence heat exchange with the environment, including changing

60 activity patterns, postural adjustments or selecting thermally-advantageous microclimates

61 (Speakman and Krol 2010, Huey et al. 2012, McFarland et al. 2015, Mason et al. 2017,

62 McFarland et al. 2019, 2020). Behavioral thermoregulation, however, may take place at the

63 expense of other behaviors critical to survival (e.g., feeding, drinking, traveling, and social

64 activity; McFarland et al. 2014, Dunbar et al. 2009).

65 Thermoregulatory mechanisms require time and resources that could otherwise be used

66 for growth and reproduction. Therefore, fitness-related activities are essentially traded and

67 prioritized according to social, ecological, and environmental factors. The fundamental challenge

68 for an endotherm is to balance these activities - and their associated costs - without operating in

69 a long-term negative energy or water balance. Species distributions are thought to be determined 
70 by sublethal impacts of thermal stress on performance rather than physiological thresholds for 71 direct temperature-related mortality (Buckley et al. 2012, Evans et al. 2015). Thus, being able to

72 predict consequences of thermal stress can provide valuable insight into understanding current

73 distributions and potential responses to climate change.

74 The most common approach to modeling species' distributions involves statistically

75 relating a species' occurrence locations with environmental predictors such as climate and land 76 cover (Elith and Leathwick 2009). The resulting $n$-dimensional space that represents the range of

77 environmental conditions at known presence locations is considered the animal's bioclimatic 78 "envelope". These envelopes are then projected onto future climate scenarios to predict changes 79 in distribution (Hijmans and Graham 2006). Taking a correlative approach to distribution 80 modeling, however, provides little insight into how environmental predictors limit distributions, 81 since the limiting processes remain implicit in the correlations (Dormann et al, 2012, Evans et al. 82 2015). Correlative approaches also require extrapolation into novel environments, such as those 83 created by climate change, increasing the risk of erroneous predictions (Buckley and Kingsolver 84 2012, Pacifici et al. 2015). In contrast, mechanistic models explicitly model the processes 85 thought to limit a species' distribution. By explicitly modeling the processes, predicted 86 distributions are based entirely on the model's predictions of where survival is possible, 87 independent of observed distributions. Mechanistic models are therefore more informative than 88 correlative models and can be applied to novel conditions without extrapolation (for 89 comprehensive comparisons of correlative and mechanistic approaches, see Kearney and Porter 90 2009, Buckley et al. 2010).

91 One mechanistic approach to understanding distributional limits is the use of biophysical 92 models, which are based on fundamental principles of heat and mass transfer, and model how an 
93 animal's morphology, physiology, and behavior interact with its environment in terms of energy,

94 dry mass and water balances to affect fitness and performance (Porter and Gates 1969; Kearney

95 and Porter 2009). A biophysical model can thus be used to quantify thermal stresses incurred by

96 an animal in any environment. These stresses include increased heat production and food

97 requirements in response to cold stress, and increased evaporative water loss and/or reduced

98 activity in response to heat stress. This quantification provides insight into how a species'

99 distribution is limited by environmental temperatures (Kearney and Porter 2009). In the context

100 of climate change, biophysical models can be used to investigate the direct impact of higher

101 environmental temperatures on an animal's thermal performance and habitat suitability across

102 the landscape. By modeling these consequences mechanistically, taking an animal's specific

103 characteristics into account, biophysical models can be used to examine how intraspecific

104 variation in morphological and physiological traits, as well as behavioral responses, might allow

105 a species to buffer the impacts of climate stress.

106 Here, we build and test a vervet monkey (Chlorocebus pygerythrus) model with Niche

107 Mapper (Porter and Mitchell 2006; hereafter, 'NM'), a biophysical modeling software package.

108 Local climates impose an important ecological constraint on primate distributions (Korstjens et

109 al. 2010, Lehmann et al. 2010), so understanding how primates respond to changes in the thermal

110 environment is essential if we are to assess how climate change will impact species survival in a

111 taxon that is already facing substantial pressure (Estrada et al. 2017). NM has been used to

112 accurately predict the energetic requirements and thermal stress as a function of environmental

113 conditions for a wide variety of animals, including the following mammals: American pika

114 (Ochotona princeps; Moyer-Horner et al. 2015), Japanese serow (Capricornus crispus; Natori

115 and Porter 2007), giant panda (Ailuropoda melanoleuca; Zhang et al. 2018), elk (Cervus elaphus; 
Long et al 2014), polar bear (Ursus maritimus; Mathewson and Porter 2013), and koala

(Phascolarctos cinereus; Briscoe et al. 2016). However, to date no study has validated whether

118 NM accurately predicts body temperatures $\left(T_{b}\right)$ in wild endotherms. $T_{b}$ is a key driver of NM's

119 calculations and thus validation of accurate $T_{b}$ predictions will provide increased confidence in

120 NM's ability to accurately predict energetic requirements and thermal stress in wild

121 environments.

122

123 a wild endotherm, the vervet monkey (Chlorocebus pygerythrus). Using a combination of direct

124 measurements and information obtained from existing literature, we parameterize a vervet

125 biophysical model. We first assess the vervet model in the controlled environment of a simulated 126 metabolic chamber by evaluating whether the model predicts a reasonable thermoneutral zone.

127 Next, we perform a series of sensitivity analyses to illustrate which morphological, physiological 128 and behavioral inputs have the biggest impact on the model's predictions of thermoneutral zone, 129 metabolic heat production, and $\mathrm{T}_{\mathrm{b}}$. Finally, using a set of models parameterized to bracket the 130 range of behaviors observed in a wild population of vervets, we use NM to make $\mathrm{T}_{\mathrm{b}}$ predictions, 131 and will compare those predictions to measurements taken in situ from the wild population. 132 Given our multiyear dataset on the $\mathrm{T}_{\mathrm{b}}$, behavior, and local climate of a wild population, we are 133 uniquely positioned to test NM's ability to predict a wild endotherm's thermal response to the 134 environment. Vervets represent an excellent model to meet this objective, as they experience a 135 wide temperature range in varied environments (Pasternak et al. 2012; McFarland et al. 2014), 136 and possess a range of behavioral and thermoregulatory adaptations (McFarland et al. 2015, $1372019,2020)$. 


\section{METHODS}

\subsection{Study site, subjects, and wild animal data collection}

141 Between 2012 and 2016, we collected field data from a population of wild vervet monkeys living 142 on the Samara Private Game Reserve in the Eastern Cape, South Africa (32²2’'S, $\left.24^{\circ} 52^{\prime} \mathrm{E}\right)$. We 143 recorded local climate at an onsite weather station (McFarland et al. 2015). This semi-arid region 144 has a seasonal climate, with hot, wet summers, and cold, dry winters. Annual rainfall is $<$ $145400 \mathrm{~mm}$, while minimum and maximum air temperatures typically range between -5 and $40^{\circ} \mathrm{C}$ 146 (McFarland et al. 2014).

As part of a long-term study of vervet monkey thermal physiology, we abdominally 148 implanted 45 vervets with body temperature data loggers that recorded core $\mathrm{T}_{\mathrm{b}}$ at five-minute 149 intervals $($ mean $=16.4 \pm 10.6$ months/monkey; Table A.1). Vervets were immobilized using 150 blow darts filled with a combination of midazolam and ketamine, and following recumbence, 151 were transported to a temporary operating theatre where they were weighed. A qualified 152 veterinarian administered the appropriate analgesic, anti-inflammatory and antibiotic medication, 153 and followed standard, ethically-approved, aseptic surgical techniques for the implantation of 154 data loggers. The vervets were allowed to recover fully in cages before being released back into 155 their group. Normal behavior resumed on the day after surgery, and no long-term sequelae were 156 observed as a consequence of surgical intervention, as confirmed by regular behavioral 157 monitoring by researchers and a veterinarian. See McFarland et al. (2015) for full details of the 158 implantation procedure. Since NM performs energy balance calculations on an hourly basis (see 159 section 2.2 below), we calculated the average hourly $\mathrm{T}_{b}$ s for male and female monkeys from the 160 five-minute observational data, allowing us to directly compare observed $T_{b}$ and NM's predicted $161 \mathrm{~T}_{\mathrm{b}}$. Vervet 24-hour $\mathrm{T}_{\mathrm{b}}$ patterns follow a square wave pattern with lower and upper modal $\mathrm{T}_{b} \mathrm{~S}$ 
162 (Lubbe et al. 2014). The lower modal $\mathrm{T}_{\mathrm{b}}$ for the current study animals (based on 479,530

163 individual vervet hour $\mathrm{T}_{\mathrm{b}}$ measurements) was $37.1^{\circ} \mathrm{C}$ and the upper modal $\mathrm{T}_{\mathrm{b}}$ was $38.6^{\circ} \mathrm{C}$ (Fig.

164 A.1a). The modal $T_{b S}$ were similar between sexes and across seasons (Fig. A.1b).

two males (2016) during their respective animal captures. In 2015, we used a tape measure to

167 measure the length and width of each animal's head, torso, arms, legs and tails. In 2016, we used 168 calipers to measure the fur depth and hair length on each of these same body parts, allowing us to 169 calculate the hair length:fur depth ratios for two subjects. We used vervet pelt reflectance values 170 measured by McFarland et al. (2016), where trapezoidal integration of each wavelength interval 171 (5nm between 250-3500nm) was scaled according to the solar energy in that interval to calculate 172 overall solar reflectivity. We measured hair diameter and density from two pelts (McFarland et 173 al. 2016) using an ocular calibration grid and micrometer with a light microscope.

174 All capture and surgical procedures were approved by the University of the 175 Witwatersrand Animal Ethics Research Committee (Protocols \# 2010/41/04 and 2015/04/14B), 176 and all animals were treated in accordance with international ethical standards. Importantly, 177 vervets were not exposed to the above surgical procedures for the purpose of the current project. 178 These $T_{b}$ data were collected as part of a longitudinal study of vervet monkey thermal 179 physiology (see, e.g., Lubbe et al. 2012; McFarland et al. 2015, 2019, 2020; Henzi et al. 2017) 180 and body temperature data collected during the study were opportunistically utilized for the 181 current study.

183 2.2 Modelling Methodology

184 2.2.1 Niche Mapper - General Description 
NM consists of a microclimate submodel and an animal submodel (Fig. 1). The

microclimate submodel uses hourly interpolation of macroclimate data (maximum and minimum

187 daily air temperatures, relative humidity, cloud cover, and wind speed), and substrate properties, 188 vegetative cover, geographic location, topography, and time of year to calculate hourly

189 environmental profiles from $2 \mathrm{~m}$ height down to the ground surface using numerical integration 190 of a one-dimensional finite difference equation in the vertical dimension. The microclimate 191 submodel also calculates sky temperatures and incoming solar radiation incident on the ground 192 that is available for absorption by the model animal. Separate environmental profiles are 193 calculated for full sun and shaded microenvironments (see Fuentes and Porter 2013 for more 194 details on the microclimate model calculations).

The animal submodel uses morphological, physiological and behavioral information about the animal along with hourly microclimate submodel outputs (Fig. 1) to iteratively solve coupled heat and mass balance equations (Porter 2016) to find the metabolic rate needed for the animal to maintain its $\mathrm{T}_{\mathrm{b}}$, accounting for convective, radiative, evaporative and solar heat fluxes with its microenvironment for each hour of the day (see Mathewson and Porter 2013 for details 200 on the heat balance calculations). Animal body parts are modelled as simple shapes (cones, 201 cylinders, ellipsoids, spheres) with well-understood heat transfer properties that enable surface 202 temperatures to be calculated based on a given $\mathrm{T}_{\mathrm{b}}$ and body part dimensions. NM models heat 203 flowing from the core to the skin surface, assuming distributed metabolic heat generation 204 throughout the flesh of each body part. For bare body parts, heat fluxes with the environment are 205 computed using the calculated skin surface temperatures. For furred body parts, heat is modeled 206 as traveling through a porous fur layer composed of a matrix of air and keratin via parallel 
207 conduction and radiative processes before heat exchange with the environment is calculated 208 (Conley \& Porter 1986).

NM solves the animal's heat balance for each hour of the day. Calculations for each hour 210 begin by computing the metabolic heat production required for the animal to maintain its starting $211 \mathrm{~T}_{\mathrm{b}}$ (specified by the user, typically an average $\mathrm{T}_{\mathrm{b}}$ ) in that hour's environmental conditions. Other 212 parameters that are allowed to be modified for thermoregulatory purposes (Fig. 1) also begin 213 each hour's calculations at their specified starting value. Thermoregulatory options are engaged 214 if the required metabolic rate is above or below that hour's target metabolic rate. Target 215 metabolic rates are either resting metabolic rate (during hours when animals are assumed to be 216 inactive) or a multiple of resting metabolic rate to simulate activity (during hours when animals 217 are assumed to be active). The user specifies whether the model animal is active or inactive 218 separately for diurnal, crepuscular, and nocturnal hours. Users can supply a species-specific 219 resting metabolic rate if data are available; otherwise the model estimates resting metabolic rate 220 using a generic mammalian regression equation based on animal mass (Gordon et al. 1972). Behavioral thermoregulatory options of selecting a different microhabitat (e.g., shade 222 seeking in the heat) or changing posture (e.g., curling/huddling up in the cold) are engaged first, 223 followed by physiological options. To minimize metabolic heat production above the target 224 range in cold environmental conditions, animals are allowed to increase pelage depth (to 225 simulate piloerection), decrease flesh thermal conductivity (to simulate vasoconstriction) and 226 reduce $\mathrm{T}_{\mathrm{b}}$. To maintain a metabolic rate in a hot environment, animals are allowed to increase 227 thermal conductivity (to simulate vasodilation), increase $\mathrm{T}_{\mathrm{b}}$, and increase surface area that is wet 228 (simulating sweating). Thermoregulation will proceed until a heat balance is reached with a 229 metabolic rate within the target range or until the model has reached the maximum or minimum 
230 value for the thermoregulatory options (e.g., the maximum or minimum $\mathrm{T}_{\mathrm{b}}$ allowed by the user).

231 If thermoregulatory options are exhausted before a metabolic rate within the user-specified

232 tolerable error (here, $\pm 2.5 \%$ ) of the target metabolic rate is reached, the model will return the metabolic rate closest to the target value that satisfies the heat balance.

\subsubsection{Vervet Animal Model Parameterization}

Using the morphometric data described above, we modeled vervets with ellipsoids for the 237 head and cylinders for all other body parts. Our over-arching objective is to validate NM's ability 238 to make accurate predictions of $\mathrm{T}_{\mathrm{b}}$. We use data collected from wild vervets to specify the 239 model's starting (i.e., average: $\left.38^{\circ} \mathrm{C}\right)$, minimum $\left(36^{\circ} \mathrm{C}\right)$ and maximum $\left(41^{\circ} \mathrm{C}\right)$ allowable $\mathrm{T}_{\mathrm{b}}$. 240 These minimum and maximum $\mathrm{T}_{\mathrm{b}}$ values are outside the bimodal distribution $\left(37-39^{\circ} \mathrm{C}\right)$ of body 241 temperature observed in this species. Although the starting temperature we define will be the 242 starting point for NM's calculation of hourly heat balance, NM's final $T_{b}$ prediction is the value 243 that allows the animal to reach an acceptable heat balance in those conditions; ranging anywhere 244 between the specified minimum and maximum $T_{b}$ values. As part of its thermoregulatory loop, $245 \mathrm{NM}$ can adjust $\mathrm{T}_{\mathrm{b}}$ in $0.1^{\circ} \mathrm{C}$ increments in order to reach an acceptable heat balance (Fig. 1).

246 Thus, any variation in predicted $T_{b}$ from the user-supplied starting $T_{b}$ is due to the model 247 predicting that $a T_{b}$ change is needed to either maintain the target metabolic rate ( $T_{b}$ increase) or 248 avoid additional metabolic heat production ( $\mathrm{T}_{\mathrm{b}}$ decrease) in that hour's environmental conditions. 249 Daily $\mathrm{T}_{\mathrm{b}}$ cycling is not programmed into the model. Any predicted $\mathrm{T}_{\mathrm{b}}$ cycling is an emergent 250 property of the hourly environmental conditions interacting with the animal model's 251 morphological, physiological, and behavioral traits. 


\subsubsection{Thermoneutral Zone (TNZ) Predictions}

Our first objective is an initial evaluation of model performance, investigating whether

the environmental temperatures at which the male and female vervets models, parameterized as described above in section 2.2.3 to be used in the wild vervet $\mathrm{T}_{\mathrm{b}}$ validations, predicts heat or cold stress (i.e., the upper and lower bound of its predicted TNZ) are reasonable. We define the upper

258 critical temperature as the air temperature at which model vervets would not be able to maintain 259 their resting metabolic rate without sweating (sensu Mitchell et al. 2018). We define the lower 260 critical temperature as the air temperature at which model vervets would need to raise their 261 metabolic heat production above the resting rate to maintain their $\mathrm{T}_{\mathrm{b}}$. In a real-world setting, air 262 temperatures combine with ground and sky radiant temperatures, wind, humidity and solar 263 radiation to create the effective temperature that the animal experiences. To identify the 264 predicted upper and lower critical temperatures (i.e., the TNZ boundaries) more clearly, we 265 placed the model animal into a simulated metabolic chamber in which all temperatures (i.e., air, 266 ground, and sky) were set to the same value and then increased in $1^{\circ} \mathrm{C}$ increments, with no solar 267 radiation, relative humidity set to $5 \%$, and wind speeds set to $0.1 \mathrm{~m} \mathrm{~s}^{-1}$. Given our definition of 268 upper critical temperature, the model vervets were not able to sweat in the metabolic chamber for 269 the purpose of identifying the predicted thermoneutral zone, since sweating would indicate that it 270 was already outside the TNZ. For the purposes of the TNZ analysis, we held the $\mathrm{T}_{\mathrm{b}}$ constant at $27138^{\circ} \mathrm{C}$. All other morphological and physiological inputs were as listed in Table 1. Because 272 experimental studies reporting TNZs rarely report the posture of the animal during the 273 measurements, we simulated vervets in both a curled posture (simulated by combining the arms, 274 legs, and torso into a single body part shape for the purposes of modeling heat exchange) and 275 uncurled posture (all body parts available for heat exchange). 


\subsubsection{Sensitivity analyses}

Our second objective is to perform a sensitivity analysis of the vervet model's

biophysical inputs to examine which inputs have the greatest effect on the NM's thermal stress predictions for the vervets. Relevant morphological and physiological NM input values (pelage

281 properties, body part dimensions, body size, resting metabolic rate, $T_{b}$ variability) were adjusted 282 from the value listed in Table 1 to assess how they affected the model's predicted upper and 283 lower critical temperatures and whole-body thermal conductivity. Whole-body thermal 284 conductivity was calculated as the slope of the predicted metabolic rate as a function of air 285 temperature below the lower critical temperature $\left(\mathrm{W}^{\circ} \mathrm{C}^{-1}\right)$. All analyses were conducted in a 286 simulated metabolic chamber, as described in section 2.2.3 with vervets being simulated as being 287 uncurled (i.e., standing with hands and feet on the ground). For all sensitivity analyses except the $288 \mathrm{~T}_{\mathrm{b}}$ variability analysis, we held the $\mathrm{T}_{\mathrm{b}}$ constant at $38^{\circ} \mathrm{C}$.

289 With three exceptions, when one parameter was being analyzed, all other inputs remained 290 at their user-supplied values listed in Table 1. First, when analyzing the effect of body size, the 291 radial and linear dimensions of the body parts were scaled up or down proportionally to ensure 292 the same body part proportions and densities. Second, when analyzing the effect of body part 293 linear dimensions, body part radial dimensions were automatically adjusted in or out to ensure 294 constant body part density (e.g., increasing linear dimensions would result in longer, thinner 295 body parts). Third, when analyzing the effect of allowable $T_{b}$ fluctuation, minimum and 296 maximum $\mathrm{T}_{\mathrm{b}}$ were set at either $\pm 0,1,2$, or $3^{\circ} \mathrm{C}$ from the $38^{\circ} \mathrm{C}$ starting point. 
We simulated wild vervets for the data collection period (2012-2016) and compared $\mathrm{T}_{\mathrm{b}}$ predictions to observed $T_{b}$ from the wild vervet study population. These simulations allowed us to test NM's ability to accurately predict $T_{b}$ and identify thermally stressful conditions. We used hourly temperatures recorded at the on-site weather station (placed in an unshaded location: see Lubbe et al. 2014 for details) to parameterize the microclimate model. Other microclimate model inputs are summarized in Table A.3. To bound potential microclimate conditions, we calculated microclimate conditions at animal height in the full sun (the hottest microclimate conditions) and in the full shade, with the ability to climb to a height where $2 \mathrm{~m}$ climate conditions prevail (i.e., the coolest microclimate conditions).

NM models will always thermoregulate to minimize deviations from the target metabolic 309 rate (i.e., resting or active) and will behaviorally thermoregulate before physiologically 310 thermoregulating, thereby minimizing variation in $T_{b}$ changes from the starting $T_{b}$. Thus, user 311 choice of allowable thermoregulatory options will affect $T_{b}$ predictions. For example, if vervets 312 were allowed to seek shade and assume any nighttime posture, NM would immediately attempt 313 to seek shade when the animal is first heat stressed during the day and start to huddle when first 314 cold stressed at night before changing its $T_{b}$. Furthermore, during any diurnal hour, NM will 315 always assume the vervet is active unless it is unable to maintain a heat balance at the active 316 metabolic rate.

317 A real animal may behave in ways that affect metabolic rate and $\mathrm{T}_{\mathrm{b}}$ for reasons unrelated 318 to thermal stress. Therefore, a single set of model assumptions in terms of habitat choice, activity 319 level, and posture is not universally applicable, and it would be inappropriate to evaluate NM's 320 performance using a single set of model assumptions. Thus, we performed the wild vervet 321 simulations with a cold animal model and a hot animal model in order to bracket possible 
322 predicted $\mathrm{T}_{\mathrm{b}} \mathrm{S}$. We parameterized the cold model to provide the lowest predicted $\mathrm{T}_{\mathrm{b}}$ for any given

323 hour. For diurnal hours the cold model was assumed to be inactive (i.e., targeting resting

327 (representing a solitary individual draped across a branch). We parameterized the hot model to provide the highest predicted $\mathrm{T}_{\mathrm{b}}$ for any given hour. During diurnal hours the hot model was assumed to be active with no access to shade or ability to climb to reach cooler temperatures. For each day within a given month we used the same activity multiplier as the active metabolic rate, with monthly multipliers varying from a low of $2.25 x$ resting metabolic rate (RMR) in the summer to a maximum of $4.5 x$ RMR in the winter. These multipliers were derived through a calibration process to obtain the closest fit between predicted and observed $\mathrm{T}_{\mathrm{b}}$ for the 2012-2013 field season simulations and correspond to a 24-hour field metabolic rate of $1.75 x$ RMR in the summer and 2.46x RMR in the winter when accounting for seasonal differences in day lengths. This activity variation is consistent with observations of higher activity in the colder months (McFarland et al. 2014; see also Cantaloup et al. 2019).

During nocturnal hours the hot model was allowed to use the most heat-conservative nocturnal body posture of huddling between other monkeys. Huddling was simulated by lumping multiple individuals together to reduce surface area available for heat exchange with the environment (Mathewson 2018) and is thought to be an important form of behavioral thermoregulation for vervets to minimize metabolic heat production overnight (McFarland et al. 2015). We assumed a warm huddling scenario to provide an upper bound of predicted nighttime $\mathrm{T}_{\mathrm{b}}$ : a vervet in between two other individuals with $75 \%$ of its torso in contact with neighbors. 
Other than the differences in behavioral parameters described above, the hot and cold

models were parametrized identically (Table 1). For nocturnal hours (i.e., when the sun is below

the horizon), the monkeys were simulated in both the hot and cold models as being inactive in a tree, where 2-m climate conditions determine the relevant microclimate. In both the hot and cold models, piloerection (allowing fur depth to increase to $50 \%$ of hair length),

350 vasodilation/vasoconstriction, sweating (allowing up to $75 \%$ of the body to be covered in sweat 351 for evaporative water loss), and $\mathrm{T}_{b}$ changes between the specified maximum and minimums were 352 all allowed for thermoregulation.

353 To evaluate the importance of shade access (McFarland et al. 2020), we ran an additional 354 simulation where we modified the cold model to not allow the model to seek shade during 355 diurnal hours. To evaluate the importance of huddling and overnight posture (McFarland et al. 356 2015; Henzi et al 2017), we ran a final simulation where we modified the hot model so rather 357 than huddling, it could only curl up at night. Curling up was simulated by combining the arms, 358 legs, and torso into a single body part shape for the purposes of modeling heat exchange 359 (representing a vervet curling its arms and legs into its torso).

360 We compared the mean observed $\mathrm{T}_{\mathrm{b}}$ for each hour to the maximum and minimum 361 predicted $\mathrm{T}_{\mathrm{b}} \mathrm{s}$ and the average of the maximum and minimum predicted $\mathrm{T}_{\mathrm{b}}$. We also evaluated 362 how well NM's bracketed range of predicted $T_{b}$ s captured the observed $T_{b} s$ by calculating the 363 number of hours that the mean observed $\mathrm{T}_{\mathrm{b}}$ for each sex was between the minimum and 364 maximum predicted $T_{b}$. Unless specifically noted when evaluating the importance of shade 365 access or huddling, the maximum $\mathrm{T}_{\mathrm{bS}}$ are from the hot model that allows huddling and the cold 366 minimum $T_{b} \mathrm{~s}$ are from the cold model that allows access to shade. 

368

Finally, we calculated several daily metrics with both the observed and predicted $\mathrm{T}_{\mathrm{b}}$ data: minimum $\mathrm{T}_{b}$, maximum $\mathrm{T}_{\mathrm{b}}$, mean $\mathrm{T}_{\mathrm{b}}$, and 24-hour amplitude of $\mathrm{T}_{\mathrm{b}}$ rhythm (difference between maximum and minimum $\mathrm{T}_{\mathrm{b}}$ ). For the observed data, we calculated these metrics based on hourly average $T_{b}$ for each sex, with the exception of 24-hour amplitude where individual amplitudes 371 were calculated and an average for each sex was computed. For the predicted data, we calculated 372 the ranges for each metric using the maximum and minimum $\mathrm{T}_{\mathrm{b}}$ predictions from the hot model 373 that allows huddling and the cold model that allows access to shade.

375 3. RESULTS

$376 \quad 3.1$ Thermoneutral Zone Prediction

377 The predicted thermoneutral zone (TNZ) for the model vervets ranged from $18^{\circ} \mathrm{C}$ (males) 378 and $19^{\circ} \mathrm{C}$ (females) to $28^{\circ} \mathrm{C}$ (both sexes) without any postural change (Fig. A.3). Allowing a 379 heat-conserving "curled" posture with arms and legs tucked into the torso reduced the lower 380 critical temperature to $6^{\circ} \mathrm{C}$ (males) and $10^{\circ} \mathrm{C}$ (females) (Fig. A.3).

3813.2 Sensitivity analyses

382 NM was most sensitive to changes in assumed resting metabolic rate, fur depth, the hair 383 length:fur depth ratio, body part length:width ratio and allowable $\mathrm{T}_{\mathrm{b}}$ range (Table 2; Figs. A.4384 A.7). Increasing resting metabolic rate or any of the pelage inputs shifted the TNZ to lower 385 temperatures, while increasing body part length:width ratio shifted the TNZ to higher 386 temperatures. Upper and lower critical temperatures increased and decreased, respectively, by 1$3872{ }^{\circ} \mathrm{C}$ for each degree the $\mathrm{T}_{\mathrm{b}}$ was able to vary from $38^{\circ} \mathrm{C}$ (Fig. A.7). The model was least sensitive 388 to changes in hair diameter and density, although halving these values from the value used in the 389 vervet model had a large effect on predicted critical temperatures (Fig. A.4). 


\subsection{Testing Niche Mapper's Ability to Predict Body Temperature}

Examples of NM's maximum $\mathrm{T}_{\mathrm{b}}$ (active in the sun during diurnal hours; inactive and

392 huddled during crepuscular and nocturnal hours) and minimum predicted $\mathrm{T}_{\mathrm{b}}$ (resting in the shade

393 during diurnal hours; inactive and uncurled alone during crepuscular and nocturnal) along with

394 the range of observed $\mathrm{T}_{\mathrm{b}}$ for a hot and cold month are shown in Figure 2.

\section{3.3.1 Diurnal Hours}

396

397

411 the observed $T_{b} s$. (e.g., hours 14:00-16:00 in Fig. 4).

\section{3.3.2 Nocturnal hours}

compared to observed $\mathrm{T}_{\mathrm{b}} \mathrm{S}$ (Fig. 3). The minimum predicted $\mathrm{T}_{\mathrm{b}}$ was typically lower than the observed $T_{b}$, while the maximum $T_{b}$ prediction typically overestimated $T_{b}$ compared to observed $\mathrm{T}_{\mathrm{b}}$. The average predicted $\mathrm{T}_{\mathrm{b}}$ clustered around the observed upper modal $\mathrm{T}_{\mathrm{b}}$. NM's $\mathrm{T}_{\mathrm{b}}$ predictions were also compared with observed $\mathrm{T}_{\mathrm{b}}$ for each hour of the day across each season (Fig. 4). For most hours, the average predicted $\mathrm{T}_{\mathrm{b}}$ was close to observed $\mathrm{T}_{\mathrm{b}}$ (see also Fig. A.8 showing how the average predicted $T_{b}$ clustered around the upper modal $T_{b}$ ), there were times when the average predicted $\mathrm{T}_{\mathrm{b}}$ over- or under-predicted the observed $\mathrm{T}_{\mathrm{b}}$ by more than $1^{\circ} \mathrm{C}(5.8 \%$ of hours for females; $8.3 \%$ of hours for males). During the earliest diurnal hours, NM over-predicts $\mathrm{T}_{\mathrm{b}}$ if any activity was assumed (e.g., average and maximum $T_{b}$ predictions for hours 04:00-05:00 in Fig. 4). For other hours, most of the over-predictions occur in the warmer months during the warmest hours of the day when the minimum NM prediction (a resting vervet) were closest to the observed $\mathrm{T}_{\mathrm{b}} \mathrm{s}$ (e.g., hours 12:00-15:00 in Fig. 4). Similarly, most of the under-predictions occur in the colder months, when the maximum NM prediction (an active vervet) were closest to .3.2 Nocturnal hours 
NM's maximum, minimum and average (of the maximum and minimum, representing a

421

422 423 424 425 426 427 428 429 430 431 432 433 within the predicted range by $\sim 20 \%$ for both sexes. Not allowing curling or huddling resulted in 434 the observed $\mathrm{T}_{\mathrm{b}}$ being within $0.5^{\circ} \mathrm{C}$ of NM's predicted $\mathrm{T}_{\mathrm{b}}$ for an uncurled vervet for $<20 \%$ of the 435 time (Table 4). 
Finally, we compared NM's predictions to observed values for several daily $\mathrm{T}_{\mathrm{b}}$ metrics

(minimum, maximum and mean $\mathrm{T}_{\mathrm{b}}$; 24-hour $\mathrm{T}_{\mathrm{b}}$ range) used to assess an animal's thermal performance (e.g., McFarland et al. 2015, Henzi et al. 2017). NM's predicted range was within $0.5^{\circ} \mathrm{C}$ of observed values for $>90 \%$ of the days for all of the daily metrics (Table 5). For days when the observed maximum $\mathrm{T}_{\mathrm{b}}$ was outside of the predicted range, $\mathrm{NM}$ tended to over-predict 441 maximum $T_{b} s$. For days when the observed minimum $T_{b}$ was outside of the predicted range, NM 442 tended to under-predict minimum $\mathrm{T}_{\mathrm{b}} \mathrm{s}$. On days when the observed mean $\mathrm{T}_{\mathrm{b}} \mathrm{S}$ were outside the 443 predicted range, the default models tended to under-predict mean daily $\mathrm{T}_{\mathrm{b}}$, driven by under444 predicting overnight $T_{b}$ in the winter months. Not allowing the animals to seek shade or use 445 different body postures at night reduced model performance (Tables A.4, A.5).

\section{4. DISCUSSION}

447 4.1 Metabolic Chamber and Sensitivity Analyses

448 To initially assess NMs performance, we placed the vervet model in a simulated 449 metabolic chamber to ensure that NM predicted a reasonable TNZ. We are unaware of any 450 studies reporting a vervet TNZ. There are TNZs reported for several other primate species, and 451 most of these report lower critical temperatures $>25^{\circ} \mathrm{C}$ (Table A.6), higher than the $18-19^{\circ} \mathrm{C}$ 452 LCT that NM predicted for vervets. However, most of these species are substantially smaller 453 than vervets and/or live in tropical areas with less ambient temperature variability these vervets 454 experience. Species within the Cercopithecidae family in Table A.6 are the most relevant points 455 of comparison in terms of size, ecological, and taxonomic similarity. There is disagreement in 456 the literature even within species, but at least one study for each Cercopithecidae species reports 457 a LCT lower than NM's prediction for vervets. This literature, together with the annual air 
temperature range that vervets encounter in the wild $\left(<0^{\circ} \mathrm{C}\right.$ to $\left.>40^{\circ} \mathrm{C}\right)$, suggest that NM's predicted TNZ $\left(18 / 19-28^{\circ} \mathrm{C}\right)$ is not unreasonable.

The sensitivity analyses show that most influential biophysical properties were fur depth, 461 hair length:fur depth ratio and body part length:width ratio, and target metabolic rate. All pelage 462 inputs used here were from direct measurements, so we can be confident in their use. The fur 463 thermal conductivities calculated by NM using these fur properties is $0.05-0.07 \mathrm{Wm}^{-1^{\circ}} \mathrm{C}^{-1}$, 464 depending on body part, consistent with the 0.03 (flattened pelt) -0.07 (backcombed pelt) $\mathrm{Wm}^{-}$ $465{ }^{1}{ }^{\circ} \mathrm{C}^{-1}$ range measured on a vervet pelt (McFarland et al. 2016). The hair length:fur depth ratio is 466 implicated in NM's simulated piloerection and is not relevant for species that lack the ability to 467 piloerect. If this option is allowed, the simulated fur thickness is allowed to increase to $50 \%$ of 468 the hair length. Thus, increasing the ratio would allow greater thermal benefits from piloerection. 469 Regarding body sizes and body part dimensions, the sensitivity analyses illustrate how the model 470 predicts that larger vervets or more compact animals will be more cold-tolerant. It is interesting 471 that the uncurled male and female models are predicted to have a similar TNZ despite males 472 being $45 \%$ larger than females. However, the females were more compact (smaller body part 473 length-to-width ratios) and had relatively thicker fur, both of which appear to offset the thermal 474 effect of smaller body size.

475 Our resting metabolic rate is justified since NM's default resting metabolic rate

476 regression provides a good approximation of resting metabolic rates measured in haplorhine 477 primates of similar size to vervets $(3-6 \mathrm{~kg})$, and interspecies variation is less than $10 \%$ from that 478 regression line (Fig. A.2, Table A.2). However, the choice of monthly activity multipliers that 479 dictate the target metabolic rate for the "active" simulations may affect our results. To analyze 480 the effect of this parameter choice, we performed a sensitivity analysis comparing the results 
481 using the activity multipliers as stated in the methods above to two alternate scenarios: 1) using a

constant multiplier of 2.75x BMR for all months of the year, and, 2) muting the seasonal

variation in activity multipliers to range from 2.5x BMR in the summer and 3.6x BMR in the winter (i.e., cutting the variation in half, as measured from deviations from the constant $2.75 \mathrm{x}$

$\mathrm{BMR}$ ). The muted response reduced the number of diurnal hours where observed $\mathrm{T}_{\mathrm{b}}$ was within the range of predicted $\mathrm{T}_{\mathrm{b}} \mathrm{s}$ by $<5 \%$ and reduced the number of diurnal hours where the predicted range was within $0.5^{\circ} \mathrm{C}$ of the observed $\mathrm{T}_{\mathrm{b}}$ by $<2 \%$ (Table A.8). Assuming a constant activity multiplier throughout the year reduced the number of diurnal hours where observed $\mathrm{T}_{\mathrm{b}}$ was within the range of predicted $\mathrm{T}_{\mathrm{b}} \mathrm{s}$ by $8-10 \%$ and reduced the number of diurnal hours where the predicted range was within $0.5^{\circ} \mathrm{C}$ of the observed $\mathrm{T}_{\mathrm{b}}$ by $<5 \%$ (Table A.8). Changing the activity multiplier assumptions has a similar effect on predicted daily maximum $T_{b}$, predicted daily mean $\mathrm{T}_{\mathrm{b}}$ and 24-hour amplitude predictions (Table A.9). Given the seasonal variation in vervet activity patterns (McFarland et al. 2014) a constant activity multiplier is unrealistic, but these results nevertheless illustrate the effect of this parameter choice. Importantly, if we were to halve the seasonal variation in activity multipliers in our models, our primary conclusions would have remained the same.

The maximum winter activity multiplier results in a 24-hour activity level of 2.46x RMR, which would be on the higher end of daily activity levels reported from limited information on primates (Simmen et al. 2015). However, reducing winter activity multipliers results in NM under-predicting more diurnal $\mathrm{T}_{\mathrm{b}}$ in the winter. An alternative explanation is that there could be undetected seasonal changes in fur properties (e.g., thicker and/or denser fur in the winter vs. summer), which would allow NM to predict higher winter $\mathrm{T}_{\mathrm{b}} \mathrm{s}$ using a lower activity multiplier. 
However, this appears unlikely, given the authors have not observed a visible change in vervet pelage between seasons.

Our sensitivity analyses identified the biophysical properties that most strongly influence

506 NM's $T_{b}$ and metabolic rate predictions. Gathering information on these parameters should

507 therefore be a priority for other researchers interested in using biophysical models to examine the 508 thermal performance of other species. To validate NM's ability to predict body temperature in 509 the current study, it was essential that we had detailed measures of, not only vervet morphology, 510 but also accurate measures of core body temperature. However, since NM's animal submodel is 511 generic, and can be used for any species, our study's validation should give confidence to those 512 interested in using NM to make predictions, in the absence of such a detailed data set. Indeed, 513 NM has been used to effectively examine the thermal performance of a range of species, 514 including extinct species in historical climate scenarios (Porter et al. 2006, Wang et al. 2018, 515 Lovelace et al. 2020).

516 If study-specific information for particular model inputs were unavailable, the existing 517 literature on a given, or closely-related, species, can often be used to provide reasonable 518 estimates of resting metabolic rate, $\mathrm{T}_{\mathrm{b}}$, the ability to pant or sweat, posture, and microclimate 519 options (e.g., shade-use). Similarly, pelage properties can often be found in the literature (or 520 reasonably estimated from similar species with values in the literature). Museum or other 521 taxidermic specimens are also good sources of obtaining necessary pelage property inputs. Body 522 part dimensions, if unavailable in the literature, can be estimated based on animal photographs, 523 that can be scaled up based on the known size of the animal (see e.g., Mathewson \& Porter 524 2013). 


\subsection{Body Temperature Predictions}

In this first test of NM's ability to predict $T_{b}$ in wild animals, predicted maximum and 528 minimum $\mathrm{T}_{b}$ bracketed the observed $\mathrm{T}_{\mathrm{b}}$ for the majority of hours (Tables 3,4$)$. Importantly, 529 although $\mathrm{T}_{\mathrm{bS}}$ in NM were allowed to fluctuate above and below the observed upper and lower 530 modal $\mathrm{T}_{\mathrm{b}} \mathrm{s}$ observed in the wild vervets, the "average" predicted $\mathrm{T}_{\mathrm{b}}$ clustered around the upper 531 modal $\mathrm{T}_{\mathrm{b}}$ during the day and the lower modal $\mathrm{T}_{\mathrm{b}}$ during the night (Fig. 3). This finding indicates 532 that NM was able to capture a vervet's typical response to fluctuating environmental conditions 533 and provides confidence that other outputs that are dependent on $\mathrm{T}_{\mathrm{b}}$, like metabolic rate and 534 evaporative water loss, are also likely to be reliable. More fundamentally, it supports the idea 535 that temporal $\mathrm{T}_{\mathrm{b}}$ variability is an emergent property of animals trying to maintain a certain 536 metabolic rate rather than animals modifying their metabolic rate to maintain a given $\mathrm{T}_{\mathrm{b}}$. 537 Deviations $>0.5^{\circ} \mathrm{C}$ between observed and the "average" predicted $\mathrm{T}_{\mathrm{b}}$ were sometimes 538 observed. However, they follow logical patterns based on the time of day and time of year. For 539 diurnal hours, most of the over-predictions occurred in the warmer months when vervets have 540 been observed to reduce activity (McFarland et al. 2014). Thus, the "average" prediction would 541 be expected to over-predict $\mathrm{T}_{\mathrm{b}}$ because the "resting" prediction would be more appropriate for 542 these hours. Similarly, most of the under-predictions occur in the colder months. On the colder 543 days vervets have been shown to increase activity and foraging time (McFarland et al. 2014), and 544 it is unlikely there will be much shade-seeking in the winter. Thus, the "average" prediction 545 would be expected to under-predict $T_{b}$ because the "active" prediction would be more 546 appropriate for these hours. Furthermore, the $T_{b}$ cycling could be an entrained daily rhythm 547 regardless of given day's air temperature (Levesque et al. 2016), even at the potential cost of 548 additional heat loss on the coldest days of the year. NM does not have a built-in $\mathrm{T}_{\mathrm{b}}$ cycling. All 
549 predicted deviations from the specified starting $\mathrm{T}_{\mathrm{b}}\left(38^{\circ} \mathrm{C}\right)$ are due to responses to environmental

conditions and the required metabolic rates to either minimize metabolic heat production $\left(\mathrm{T}_{\mathrm{b}}\right.$ reductions in cold conditions) or to maintain minimum metabolic heat production ( $\mathrm{T}_{\mathrm{b}}$ increases in hot conditions).

More activity than usual on a given day could also cause NM to under-predict daytime $\mathrm{T}_{\mathrm{b}}$ 554 because our modeling assumed the same activity level for all days within a month for its "active" 555 prediction. NM's T $\mathrm{b}$ predictions also do not include the heat increment of feeding, potentially 556 leading to under-predictions in post-feeding hours. Occasional swimming and drinking of cool 557 water have also been observed in this group (McFarland et al. 2020), which could account for 558 some $\mathrm{T}_{\mathrm{b}}$ over-predictions in the warmer months. Finally, we do not simulate the effect of rainfall 559 cooling the microenvironment or wetting the vervets' pelage, which could result in some $\mathrm{T}_{\mathrm{b}}$ 560 over-predictions.

561 Regarding nocturnal $\mathrm{T}_{\mathrm{b}}$, for the first hours after sunset, NM under-predicts $\mathrm{T}_{\mathrm{b}}$ (hours 562 17:00 and 18:00 in Fig. 5). This is likely due to NM assuming an immediate metabolic rate 563 reduction from active to resting to occur at sundown. In reality, there may be some crepuscular 564 activity of vervets in the trees as they settle down for the night, and vervets may have a more 565 gradual metabolic rate reduction from active to resting. While the most common average 566 nocturnal prediction was close to the observed $T_{b}$ (see Fig. A.9) there are hours when the 567 "average" prediction over- or under-predicts the observed $\mathrm{T}_{\mathrm{b}}$ by $>2{ }^{\circ} \mathrm{C}$. These discrepancies could 568 result from the majority of individuals in the group choosing a more or less heat-conserving 569 posture on certain nights, causing the "average" prediction to over-predict $\mathrm{T}_{\mathrm{b}} \mathrm{S}$ on hot nights (e.g., 570 if most individuals choose to stretch out) or to under-predict $\mathrm{T}_{\mathrm{bS}}$ on cold nights (e.g., if most 571 individuals choose to huddle). 
Some over-predictions could also be due to the observed $\mathrm{T}_{\mathrm{b}}$ cycling potentially being an

entrained rhythm that occurs daily, even if the nighttime $T_{b}$ reduction is not necessary to

minimize heat loss on a particular day as discussed above with diurnal $\mathrm{T}_{\mathrm{b}}$. Some under-

575 predictions could be due to vervets increasing metabolic rates to defend their lower modal $\mathrm{T}_{\mathrm{b}}$.

576 For example, in some conditions it could be worth the extra metabolic expenditure to maintain a

577 preferred $T_{b}$, provided that sufficient food resources are available to supply this additional

578 energetic demand. In contrast, NM's thermoregulatory decision-making always chooses to

579 minimize metabolic heat production and will reduce $\mathrm{T}_{\mathrm{b}}$ in such situations. Specific to females,

580 female reproductive state or having a dependent infant could explain some discrepancies.

581 Females with a clinging infant will have less heat loss to the environment, and gestational

582 hypothermia was observed in pregnant females.

5834.3 Study implications

584 Vervets, like all endotherms, must balance maintaining their body temperature with the

585 thermoregulatory costs incurred to do so, all the while engaging in activities necessary for

586 survival and reproduction. A biophysical model that can accurately model an animal's

587 fundamental energetic interactions with its environment allows quantification of

588 thermoregulatory costs (e.g., increased metabolic heat production or evaporative water loss

589 requirements, reduced activity time) and exploration of other questions about the fitness

590 implications of a species' morphology, physiology and behavior in relation to its environment.

591 For example, our results here provide support for the ideas of Lubbe et al. (2014), McFarland et

592 al. $(2015,2016)$, and Henzi et al. (2017), that the observed heterothermy and huddling help

593 improve fitness by reducing energetic costs during the cold winters experienced by this vervet

594 group (as evidenced by NM utilizing an overnight $\mathrm{T}_{\mathrm{b}}$ lower than the starting point $\mathrm{T}_{\mathrm{b}}$ to minimize 
metabolic heat production needed to maintain resting metabolic rate and huddled model $\mathrm{T}_{\mathrm{b}}$ predictions providing the best match to observed $\mathrm{T}_{\mathrm{b}}$ in the winter). Such models can also provide insight into the importance of certain habitat characteristics, such as shade availability, to reduce heat-related costs or access to water to facilitate the use of evaporative cooling to thermoregulate (McFarland et al. 2020).

As illustrated by our sensitivity analyses showing how body size and limb dimension affect thermal tolerance, such a model could also be used to investigate whether spatial variation in morphology across a species' range could confer energetic advantages (e.g., Bergmann's and Allen's rule). Biophysical models could be also be used to explore how disparate morphology, physiology and/or behavior between sympatric species could play a role in niche partitioning. Since the microclimate model can be parameterized with any set of environmental conditions, similar analyses could be extended into the past to explore past distributions and/or morphological changes from present may have been necessary for the species to survive in past environmental conditions (e.g., Mathewson et al. 2017, Lovelace et al. 2020). Such investigations could provide insight into the evolutionary history of a species.

Looking forward in time, having an accurate biophysical model can provide insight into species responses to changing environments, either from climate change or land cover changes. In some places natural forest is being replaced by monocrop tree plantations, presumably resulting in hotter and drier environments that may impose thermoregulatory stress on some animals and affect the likelihood that such environments could serve as suitable habitat (Spehar and Rayadin 2017). In the context of exploring species' response to climate change, biophysical models enable a mechanistic approach to species distribution modeling. Such models allow researchers to investigate how direct effects of the climate on animals (e.g., enforced resting to 


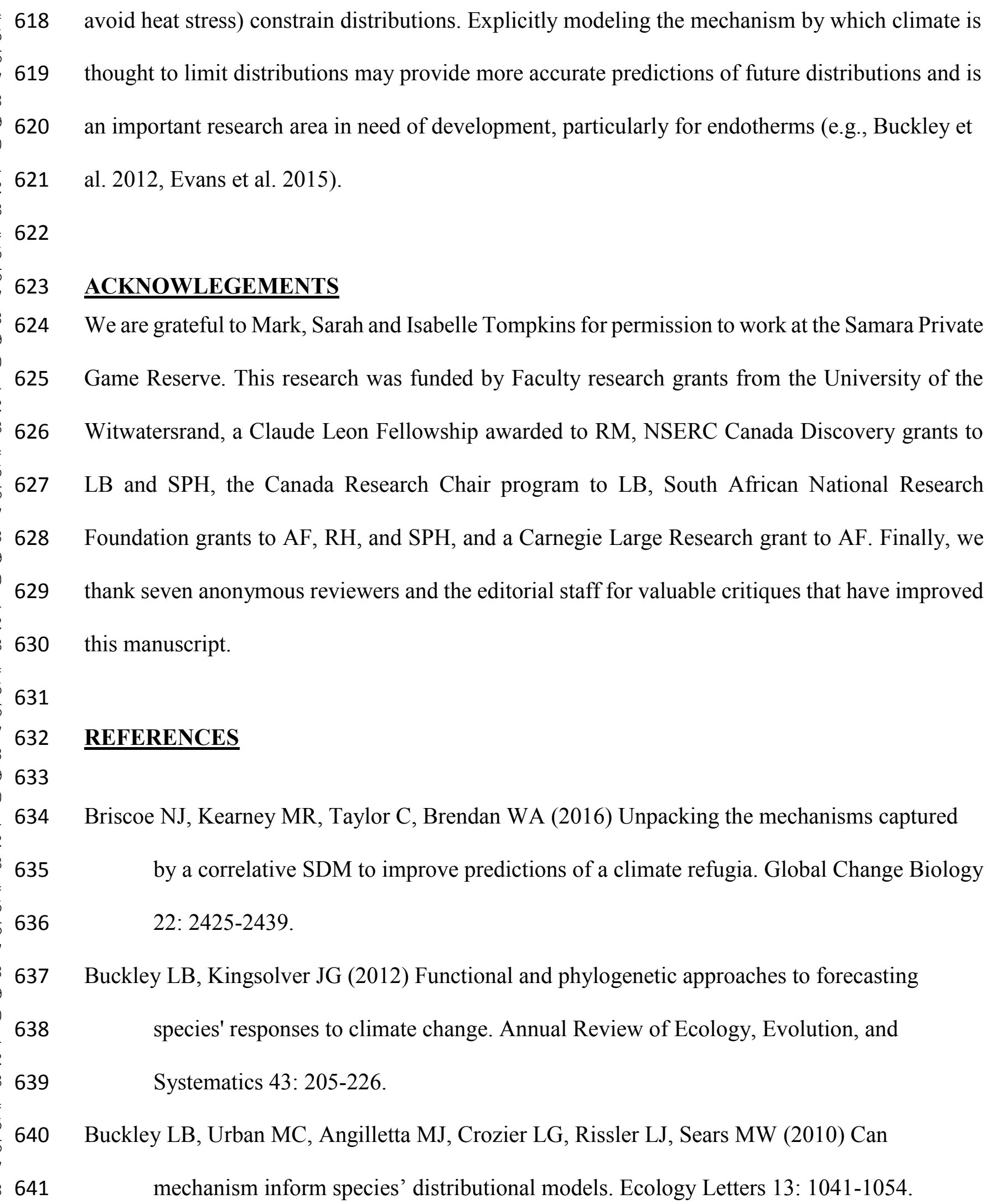
618 avoid heat stress) constrain distributions. Explicitly modeling the mechanism by which climate is 619 thought to limit distributions may provide more accurate predictions of future distributions and is 620 an important research area in need of development, particularly for endotherms (e.g., Buckley et 621 al. 2012, Evans et al. 2015).

624 We are grateful to Mark, Sarah and Isabelle Tompkins for permission to work at the Samara Private 625 Game Reserve. This research was funded by Faculty research grants from the University of the 626 Witwatersrand, a Claude Leon Fellowship awarded to RM, NSERC Canada Discovery grants to 627 LB and SPH, the Canada Research Chair program to LB, South African National Research 628 Foundation grants to AF, RH, and SPH, and a Carnegie Large Research grant to AF. Finally, we 629 thank seven anonymous reviewers and the editorial staff for valuable critiques that have improved 630 this manuscript.

631

632 REFERENCES

634 Briscoe NJ, Kearney MR, Taylor C, Brendan WA (2016) Unpacking the mechanisms captured 635 by a correlative SDM to improve predictions of a climate refugia. Global Change Biology $63622: 2425-2439$.

637 Buckley LB, Kingsolver JG (2012) Functional and phylogenetic approaches to forecasting 638 species' responses to climate change. Annual Review of Ecology, Evolution, and 639 Systematics 43: 205-226.

640 Buckley LB, Urban MC, Angilletta MJ, Crozier LG, Rissler LJ, Sears MW (2010) Can 641 mechanism inform species' distributional models. Ecology Letters 13: 1041-1054. 

642 643

8

Buckley LB, Hurlbert AH, Jetz W (2012) Broad-scale ecological implications of ectothermy and endothermy in changing environments. Global Ecology and Biogeography 21: 873-885.

Cantaloup C, Borgeaud C, Wubs M, van de Wall E. 2019. The effect of social and ecological factors on the time budget of wild vervet monkeys. Ethology 125: 902-913.

Cho BT, editor (1969) Advanced Heat Transfer. Urbana, IL: U Illinois Press. 459 pp.

647 Conley KE, Porter WP (1986) Heat loss from deer mice (Peromyscus): evaluation of seasonal limits to thermoregulation. Journal of Experimental Biology 126: 249-269.

Dunbar RIM, Korstjens AH, Lehmann J (2009) Time as an ecological constraint. Biological Reviews 84: 413-429.

Dormann, CF, Schymanski SJ, Cabral J, et al. (2012) Correlation and process in species distribution models: bridging a dichotomy. Journal of Biogeography 39: 2119-2131.

Elith J, Leathwick JR. (2009) Species distribution models: ecological explanation and prediction across time and space. Annual Review of Ecology, Evolution, and Systematics 40: 677697.

Estrada A, Garber PA, Rylands AB et al. (2017) Impending extinction crisis of the world's primates: why primates matter. Science Advances 3: e1600946

Evans TG, Diamond SE, Kelly MW (2015) Mechanistic species distribution modelling as a link between physiology and conservation. Conservation Physiology 3: doi:10.1093/conphys/cov056

661 Fuentes M, Porter WP (2013) A new approach to model soil temperature: using microclimate 662 models to predict the impacts of climate change on sea turtles. Ecological Modeling 251: $663 \quad 150-157$ 
664 Fuller A, Dawson T, Helmuth B, Hetem RS, Mitchell D, Maloney SK (2010) Physiological mechanisms in coping with climate change. Physiological and Biochemical Zoology 83: 713-720.

Fuller A, Mitchell D, Maloney SK, Hetem RS (2016) Towards a mechanistic understanding of the responses of large terrestrial mammals to heat and aridity associated with climate change. Climate Change Responses 3: 10.

Gordon MS, Bartholomew GA, Grinnell AD, Jorgensen CB, White FN (1972) Animal Physiology: Principles \& Adaptations (2nd ed). Macmillan Publ. Co., London. 592 pp.

Henzi SP, Hetem R, Fuller A, Maloney SK, Young C, Mitchell D, Barrett L, McFarland R (2017) Consequences of sex-specific sociability for thermoregulation in male vervet monkeys during winter. Journal of Zoology 302: 193-200.

675 Hetem RS, Maloney SK, Fuller A, Mitchell D (2016) Heterothermy in large mammals: 676 inevitable or implemented. Biological Reviews 91: 187-205.

677 Hijmans RJ, Graham CH (2006) The ability of climate envelope models to predict the effect of 678 climate change on species distributions. Global Change Biology 12: 2272-2281.

679 Huey RB, Kearney MR, Krockenberger A, Holtum JAM, Jess M, Williams SE (2012) Predicting 680 organismal vulnerability to climate warming: roles of behaviour, physiology and 681 adaptation. Philosophical Transactions of The Royal Society B. 36: 1665-1679.

682 Kearney M, Porter WP (2009) Mechanistic niche modelling: combining physiological and spatial 683 data to predict species' ranges. Ecology Letters 12: 334-350.

684 Korstjens AH, Lehmann J, Dunbar RIM (2010) Resting time as an ecological constraint on 685 primate biogeography. Animal Behaviour 79: 361-374. 

696

Lacombe A (2002) Effects of temperature on metabolism, ventilation, and oxygen extraction in the Southern Brown Bandicoot Isoodon obesulus (Marsupialia: Peramelidae). Physiological and Biochemical Zoology 4: 405-411.

Lehmann J, Korstjens AH, Dunbar RIM (2010) Apes in a changing world - the effects of global warming on the behavior and distribution of African apes.

Levesque DL, Nowack J, Stawski C (2016) Modelling mammalian energetics: the heterothermy problem. Climate Change Responses 3: 7.

Long RA, Bowyer RT, Porter WP, Mathewson PD, Monteith KL, Kie JG (2014) Behaviour and nutritional condition buffer a large-bodied endotherm against direct and indirect effects of climate. Ecological Monographs 84: 513-532.

Lovelace DM, Hartman SA, Mathewson PD, Linzmeier BJ, Porter WP. (2020) Modeling Dragons: Using linked mechanistic physiological and microclimate models to explore environmental, physiological, and morphological constraints on the early evolution of dinosaurs. PLOS ONE 15:e0223872

Lubbe A, Hetem RS, McFarland R, et al. (2014) Thermoregulatory plasticity in free-ranging vervet monkeys, Chlorocebus pygerythrus. Journal of Comparative Physiology B., Biochemical, systemic, and environmental physiology 184:799-809.

Mason THE, Brivio F, Stephens PA, Apollonio M, Grignolio S (2017) The behavioral trade-off between thermoregulation and foraging in a heat-sensitive species. Behavioral Ecology 28: $908-918$.

Mathewson PD (2018) Biophysical models as tools to improve understanding of endotherm responses to environmental change. $\mathrm{PhD}$ dissertation, Department of Zoology, University of Wisconsin, Madison, Wisconsin, USA. 
Mathewson PD, Porter, WP (2013) Simulating polar bear energetics during a seasonal fast using a mechanistic model. PLoS One 8: e72863.

Mitchell D, Fuller A, Maloney SK (2009) Homeothermy and primate bipedalism: is water shortage or solar radiation the main threat to baboon (Papio hamadryas) homeothermy? Journal of Human Evolution 56: 439-446.

Mitchell D, Snelling EP, Hetem RS, Maloney SK, Strauss WM, Fuller A (2018) Revisiting concepts of thermal physiology: predicting responses of mammals to climate change. Journal of Animal Ecology 87: 956-973.

McFarland R, Barrett L, Boner R, Freeman NJ, Henzi SP (2014) Behavioral flexibility of vervet monkeys in response to climatic and social variability. American Journal of Physical Anthropology 154:357-364.

McFarland R, Fuller A, Hetem RS, Mitchell D, Maloney SK, Henzi SP, Barrett L (2015) Social integration confers thermal benefits in a gregarious primate. Journal of Animal Ecology $84: 871-878$.

McFarland R, Henzi S, Barrett L (2019) The social and thermal competence of wild vervet monkeys. In Turner T (Ed.): Savanna monkeys: the genus Chlorocebus (pp. 119-207). Cambridge University Press.

McFarland R, Barrett L, Fuller A, Hetem RS, Maloney SK, Mitchell D \& Henzi SP (2020) Keeping cool in the heat: Behavioral thermoregulation and body temperature patterns in wild vervet monkeys. American Journal of Physical Anthropology 171: 407-418.

McFarland R, Henzi SP, Barrett L, Wanigaratne A, Coetzee E, Fuller A, Hetem RS, Mitchell D, Maloney SK (2016) Thermal consequences of increased pelt loft infer an additional utilitarian function for grooming. American Journal of Primatology 78: 456-461. 
732 McFarland R, Barrett L, Fuller A, Hetem RS, Maloney SK, Mitchell D \& Henzi SP. 2019.

Keeping cool in the heat: Behavioral thermoregulation and body temperature patterns in wild vervet monkeys. American Journal of Physical Anthropology 171: 407-418.

Moyer-Horner L, Mathewson PD, Jones G, Kearney MR, Porter WP (2015) Modeling behavioral thermoregulation in a climate change sentinel. Ecology and Evolution 5: 5810-5822.

Müller EF, Kamau JMZ, Maloiy GMO (1983) A comparative study of basal metabolism and thermoregulation in a folivorous (Colobus guereza) and an omnivorous (Cercopithecus mitis) primate species. Comparative Biochemistry and Physiology. A, Comparative physiology 74: 319-322.

Natori Y, Porter WP (2007) Model of Japanese Serow (Capricornis crispus) energetics predicts distribution on Honshu, Japan. Ecological Applications 17: 1441-1459.

New M, Lister D, Hulme M, Makin I (2002) A high-resolution data set of surface climate over global land areas. Climate Research 21: 1-25.

Pacifici M, Foden WB, Visconti P, et al. (2015) Assessing species vulnerability to climate change. Nature Climate Change 5: 215-224.

Pasternak G, Brown LR, Kienzle S, Fuller A, Barrett L, Henzi SP (2013) Population ecology of vervet monkeys in a high latitude, semi-arid riparian woodland. Koedoe 55:1-9.

749 Porter WP (2016) Heat Balances in Ecological Contexts. A Biogeoscience Approach to 750 Ecosystems. E. A. Johnson and Y. E. Martin. Cambridge, Cambridge University Press: $751 \quad 49-87$

752 Porter WP, Gates DM (1969) Thermodynamic equilibria of animals with environment. $753 \quad$ Ecological Monographs 39: 227-244. 

754 755 756 757 758 759 760 761 762 25

Porter WP, Mitchell JW (2006) Method and system for calculating the spatial-temporal effects of climate and other environmental conditions on animals. http://www.warf.org/technologies.jsp?ipnumber=P01251US

Porter WP, Vakharia N, Klousie WD, Duffy D (2006) Po'ouli landscape bioinformatics models predict energetics, behavior, diets, and distribution on Maui. Integrative and Comparative Biology 46: 1143-1158.

R Core Team (2017) R: A language and environment for statistical computing. R Foundation for Statistical Computing, Vienna, Austria. URL https://www.R-project.org/.

Seebacher F, Little AG (2017) Plasticity of performance curves can buffer reaction rates from body temperature variation in active endotherms. Frontiers in Physiology 8: 575 doi: 10.3389/fphys.2017.00575

Simmen B, Darlu P, Hladik CM, Pasquet P. 2015. Scaling of free-ranging primate energetics with body mass predicts low energy expenditure in humans. Physiology \& Behavior 138: 193-199.

768 Smith NP, Barclay CJ, Loiselle DS (2005) The efficiency of muscle contraction. Progress in $769 \quad$ Biophysics \& Molecular Biology 88: 1-58.

770 Speakman JR, Krol E (2010) Maximal heat dissipation capacity and hyperthermia risk: neglected 771 key factors in the ecology of endotherms. Journal of Animal Ecology 79: 726-746.

772 Spehar SN, Rayadin Y (2017) Habitat use of Bornean orangutans (Pongo pygmaeus morio) in an 773 industrial forestry plantation in East Kalimantan, Indonesia. International Journal of $774 \quad$ Primatology 38: 358-384.

775 Urban MC, Bocedi G, Hendry AP, et al. (2016) Improving the forecast for biodiversity under climate change. Science 353: 6304 
Wang Y, Porter W, Mathewson PD, Miller PA, Graham R, Williams JW. 2018. Mechanistic modeling of environmental drivers of woolly mammoth carrying capacity declines on St. Paul Island. Ecology 99: 2721-2730.

Zhang Y, Mathewson PD, Zhang Q, Porter WP, Ran J (2018) An ecophysiological perspective on likely giant panda habitat responses to climate change. Global Change Biology 24: 
Table 1. Relevant biophysical properties used to parameterize Niche Mapper's animal model for vervet monkeys. Data are sourced from the current study (mean \pm S.D.) unless marked with superscript. Variation is shown to demonstrate variability between individuals to provide additional context for the sensitivity analyses; mean values used in the modeling. These inputs were used in the thermoneutral zone and wild vervet $\mathrm{T}_{\mathrm{b}}$ validation modeling and were the starting points for the sensitivity analyses.

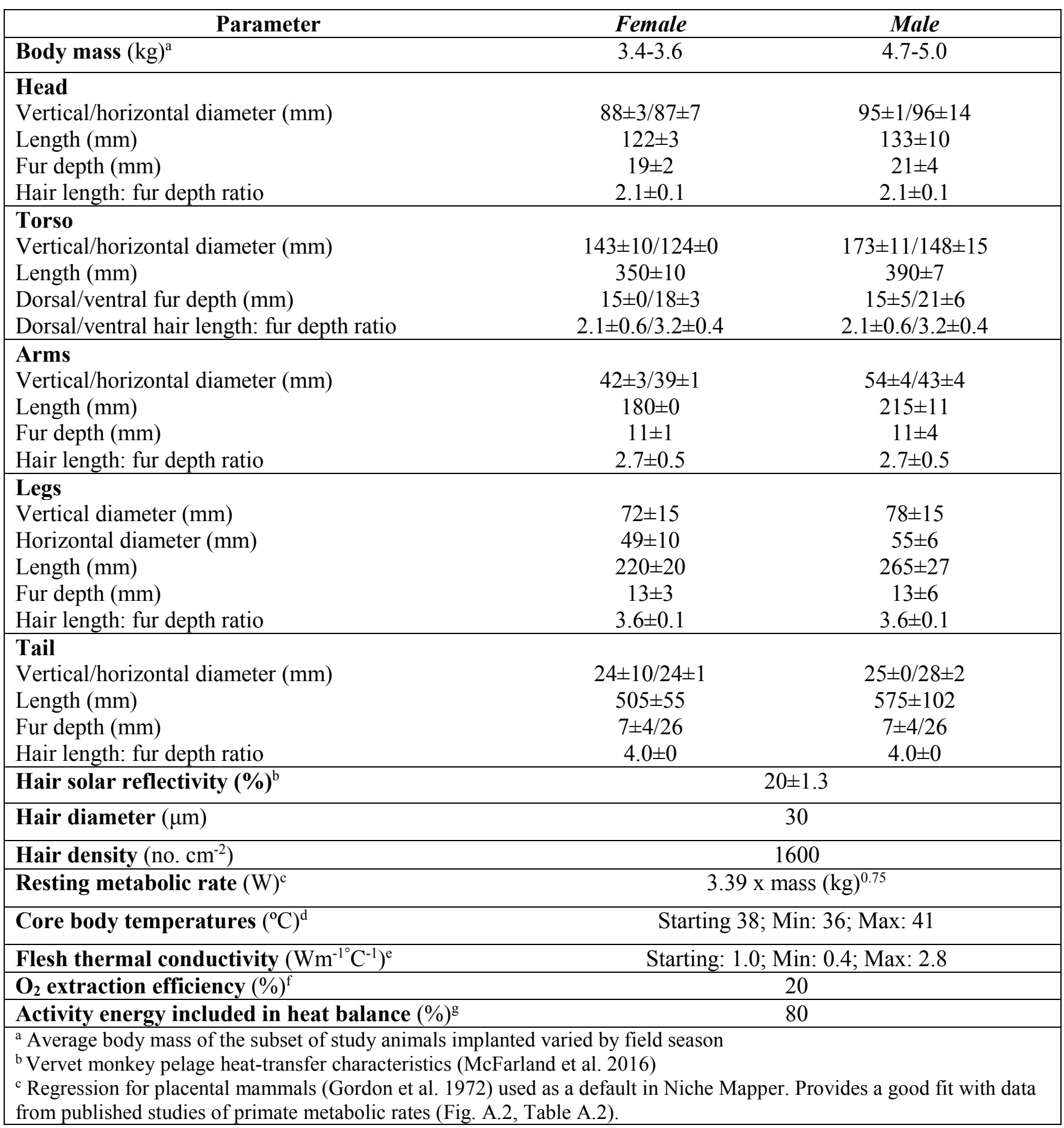



analysis

${ }^{\mathrm{d}}$ Thermophysical property data on biological media, including a cold living hand $\left(0.34 \mathrm{Wm}^{-1} \mathrm{C}^{-1}\right)$, very warm living skin $\left(2.8 \mathrm{Wm}^{-1} \mathrm{C}^{-1}\right)($ Cho 1969).

${ }^{\mathrm{e}}$ Mammal $\mathrm{O}_{2}$ extraction efficiency is typically $20 \%$ (Lacombe 2002).

${ }^{\mathrm{f}}$ Based on measurements of mammalian muscle efficiency being $\sim 20 \%$ as measured in rats and mice (Smith et al. 2005). 
Table 2. Summary of vervet model sensitivity analysis results showing the changes in whole body thermal conductivity (WBTC), upper critical air temperature (UCT) and lower critical air temperature (LCT) in response to $10 \%$ and $25 \%$ changes in key biophysical parameters. Values shown are for the female model; similar trends were observed for the male model. $\mathrm{NC}=\mathrm{No}$ change.

\begin{tabular}{|c|c|c|c|c|c|}
\hline & & $\begin{array}{c}10 \% \\
\text { Increase }\end{array}$ & $\begin{array}{c}10 \% \\
\text { Decrease }\end{array}$ & $\begin{array}{c}25 \% \\
\text { Increase }\end{array}$ & $\begin{array}{c}25 \% \\
\text { Decrease }\end{array}$ \\
\hline \multirow{3}{*}{ Fur depth } & WBTC & $-3 \%$ & $6 \%$ & $-13 \%$ & $+22 \%$ \\
\hline & UCT & $-1^{\circ}$ & $+1^{\circ}$ & $-1^{\circ}$ & $+2^{\circ}$ \\
\hline & LCT & $\mathrm{NC}$ & $+2^{\circ}$ & $-2^{\circ}$ & $+3^{\circ}$ \\
\hline \multirow{3}{*}{ Hair density } & WBTC & $-3 \%$ & $3 \%$ & $-6 \%$ & $+9 \%$ \\
\hline & UCT & $\mathrm{NC}$ & $+1^{\circ}$ & $\mathrm{NC}$ & $+1^{\circ}$ \\
\hline & LCT & $-1^{\circ}$ & $+1^{\circ}$ & $-2^{\circ}$ & $+2^{\circ}$ \\
\hline \multirow{3}{*}{ Hair diameter } & WBTC & $-3 \%$ & $3 \%$ & $-6 \%$ & $+9 \%$ \\
\hline & UCT & $\mathrm{NC}$ & $+1^{\circ}$ & $\mathrm{NC}$ & $+1^{\circ}$ \\
\hline & LCT & $-1^{\circ}$ & $+1^{\circ}$ & $-1^{\circ}$ & $+2^{\circ}$ \\
\hline \multirow{3}{*}{$\begin{array}{l}\text { Hair length: } \\
\text { fur depth ratio }\end{array}$} & WBTC & $-9 \%$ & $+9 \%$ & $-20 \%$ & $+34 \%$ \\
\hline & UCT & $\mathrm{NC}$ & $+1^{\circ}$ & $\mathrm{NC}$ & $+1^{\circ}$ \\
\hline & $\mathrm{LCT}$ & $-2^{\circ}$ & $+2^{\circ}$ & $-6^{\circ}$ & $+5^{\circ}$ \\
\hline \multirow{3}{*}{$\begin{array}{l}\text { Total body } \\
\text { mass }\end{array}$} & WBTC & $2 \%$ & $11 \%$ & $-8 \%$ & $+21 \%$ \\
\hline & UCT & $\mathrm{NC}$ & $+1^{\circ}$ & $\mathrm{NC}$ & $+1^{\circ}$ \\
\hline & LCT & $\mathrm{NC}$ & $+1^{\circ}$ & $-1^{\circ}$ & $+2^{\circ}$ \\
\hline \multirow{3}{*}{$\begin{array}{l}\text { Body part } \\
\text { lengths }\end{array}$} & WBTC & $+6 \%$ & $-9 \%$ & $+16 \%$ & $-17 \%$ \\
\hline & UCT & $+1^{\circ}$ & $-1^{\circ}$ & $+2^{\circ}$ & $-2^{\circ}$ \\
\hline & LCT & $+1^{\circ}$ & $-1^{\circ}$ & $+3^{\circ}$ & $-5^{\circ}$ \\
\hline \multirow{3}{*}{$\begin{array}{l}\text { Resting } \\
\text { Metabolic } \\
\text { Rate }\end{array}$} & WBTC & $\mathrm{NC}$ & $\mathrm{NC}$ & $\mathrm{NC}$ & $\mathrm{NC}$ \\
\hline & UCT & $-1^{\circ}$ & $+1^{\circ}$ & $-3^{\circ}$ & $+3^{\circ}$ \\
\hline & LCT & $-2^{\circ}$ & $+2^{\circ}$ & $-6^{\circ}$ & $+6^{\circ}$ \\
\hline
\end{tabular}


Table 3. Percentage of diurnal hours in the 2012-2016 field seasons $(n=14,037)$ that the mean observed vervet body temperature $\left(\mathrm{T}_{\mathrm{b}}\right)$ was within NM's predicted $\mathrm{T}_{\mathrm{b}}$ range (encompassing an active individual in full sun and an inactive individual with and without access to shade). Also shown are the percentage of hours that the observed $\mathrm{T}_{\mathrm{b}}$ was within $0.5^{\circ}$ or $1^{\circ} \mathrm{C}$ of the predicted range. In parentheses are the number of hours for which the predicted range was over/under the observed $T_{b}$. Removing shade access increased the number of hours that NM overpredicted $T_{b}$.

\begin{tabular}{|c|c|c|c|}
\hline & & Shade Available & No Shade Available \\
\hline \multirow{6}{*}{$\begin{array}{l}\frac{\mathscr{Q}}{\tilde{J}} \\
\underset{0}{0} \\
\end{array}$} & Within Range & $72.6 \%$ & $54.4 \%$ \\
\hline & & $(1669 / 2018)$ & $(4108 / 2018)$ \\
\hline & Within $0.5^{\circ} \mathrm{C}$ & $93.7 \%$ & $84.9 \%$ \\
\hline & & $(378 / 472)$ & $(1563 / 472)$ \\
\hline & Within $1.0^{\circ} \mathrm{C}$ & $99.4 \%$ & $96.6 \%$ \\
\hline & & $(51 / 25)$ & $(437 / 25)$ \\
\hline \multirow{6}{*}{$\frac{\mathscr{d}}{\sum^{\pi}}$} & Within Range & $67.6 \%$ & $48.8 \%$ \\
\hline & & $(1940 / 2418)$ & $(4466 / 2418)$ \\
\hline & Within $0.5^{\circ} \mathrm{C}$ & $91.3 \%$ & $82.3 \%$ \\
\hline & & $(621 / 542)$ & $(1843 / 542)$ \\
\hline & Within $1.0^{\circ} \mathrm{C}$ & $98.8 \%$ & $95.4 \%$ \\
\hline & & $(131 / 31)$ & $(587 / 31)$ \\
\hline
\end{tabular}


Table 4. Percentage of nocturnal hours in the 2012-2016 field seasons $(n=13443)$ that the mean observed vervet body temperature $\left(\mathrm{T}_{\mathrm{b}}\right)$ was within NM's predicted $\mathrm{T}_{\mathrm{b}}$ range (encompassing different body postures). Also shown are the percentage of hours that the observed $\mathrm{T}_{\mathrm{b}}$ was within $0.5^{\circ}$ or $1^{\circ} \mathrm{C}$ of the predicted range. In parentheses are the number of hours for which the range predicted by NM was over/under the observed $\mathrm{T}_{\mathrm{b}}$. "Stretched only" refers to only modeling a lone, uncurled individual (no range); "Stretched + curled" refers the range of $\mathrm{T}_{\mathrm{b}} \mathrm{s}$ predicted between an uncurled individual and a curled (arms and legs tucked into torso) individual; "Stretched + curled + huddled" refers to the range of $\mathrm{T}_{b} \mathrm{~s}$ predicted between an uncurled individual and an individual huddled between two others.

\begin{tabular}{|c|c|c|c|c|}
\hline & & $\begin{array}{c}\text { Stretched + } \\
\text { curled + huddled }\end{array}$ & $\begin{array}{c}\text { Stretched + } \\
\text { curled }\end{array}$ & Stretched only \\
\hline \multirow{6}{*}{ 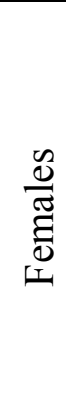 } & Within Range & $70.4 \%$ & $45.7 \%$ & \\
\hline & & $(750 / 3230)$ & $(750 / 6553)$ & NA \\
\hline & Within $0.5^{\circ} \mathrm{C}$ & $87.8 \%$ & $66.5 \%$ & $14.9 \%$ \\
\hline & & $(215 / 1424)$ & $(215 / 4292)$ & $(215 / 11228)$ \\
\hline & Within $1.0^{\circ} \mathrm{C}$ & $98 \%$ & $89.8 \%$ & $53 \%$ \\
\hline & & $(43 / 228)$ & $(43 / 1330)$ & $(43 / 6277)$ \\
\hline \multirow{6}{*}{$\frac{\sqrt{0}}{\tilde{\pi}}$} & Within Range & $73.4 \%$ & $53.1 \%$ & \\
\hline & & $(857 / 2715)$ & $(857 / 5450)$ & NA \\
\hline & Within $0.5^{\circ} \mathrm{C}$ & $90.4 \%$ & $74.9 \%$ & $18.4 \%$ \\
\hline & & (256/1039) & $(256 / 3114)$ & $(256 / 10711)$ \\
\hline & Within $1.0^{\circ} \mathrm{C}$ & $98.1 \%$ & $92.3 \%$ & $60.2 \%$ \\
\hline & & $(45 / 217)$ & $(45 / 989)$ & $(45 / 5308)$ \\
\hline
\end{tabular}


Table 5. Percentage of days in the 2012-2016 field seasons $(n=1145)$ that the mean observed minimum, maximum, average, and 24 hour-amplitude vervet body temperature $\left(\mathrm{T}_{\mathrm{b}}\right)$ was within the boundaries of NM's predicted $\mathrm{T}_{\mathrm{b}}$ between the coldest model (lone monkey stretched out at night; resting in shade during the day) and the warmest model (huddled at night; active in sun during the day). Also shown are the percentage of days that the observed metric was within $0.5^{\circ}$ or $1^{\circ} \mathrm{C}$ of the predicted range. In parentheses are the number of days for which the range predicted by NM was over/under the mean observed metric.

Female

Male

\begin{tabular}{|c|c|c|c|c|}
\hline \multirow{3}{*}{$\underset{\Xi}{\stackrel{\Xi}{\Xi}}$} & \multirow{3}{*}{$\Leftrightarrow$} & Within Range & $82 \%(17 / 189)$ & $87.3 \%(48 / 97)$ \\
\hline & & Within $0.5^{\circ} \mathrm{C}$ & $91 \%(5 / 98)$ & $97.4 \%(5 / 25)$ \\
\hline & & Within $1.0^{\circ} \mathrm{C}$ & $99.1 \%(1 / 9)$ & $99.7 \%(0 / 3)$ \\
\hline \multirow{3}{*}{ 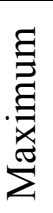 } & \multirow{3}{*}{ 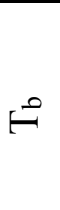 } & Within Range & $78.4 \%(139 / 108)$ & $72.8 \%(146 / 165)$ \\
\hline & & Within $0.5^{\circ} \mathrm{C}$ & $96.2 \%(33 / 10)$ & $94.9 \%(42 / 16)$ \\
\hline & & Within $1.0^{\circ} \mathrm{C}$ & $99 \%(11 / 0)$ & $99.1 \%(10 / 0)$ \\
\hline \multirow{3}{*}{ 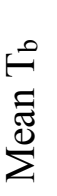 } & & Within Range & $90.4 \%(29 / 81)$ & $91.3 \%(39 / 61)$ \\
\hline & & Within $0.5^{\circ} \mathrm{C}$ & $99.8 \%(0 / 2)$ & $99.6 \%(1 / 4)$ \\
\hline & & Within $1.0^{\circ} \mathrm{C}$ & $100 \%(0 / 0)$ & $100 \%(0 / 0)$ \\
\hline \multirow{3}{*}{ 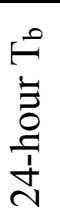 } & \multirow{3}{*}{ 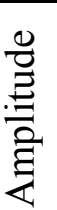 } & Within Range & $97.3 \%(15 / 16)$ & $93.9 \%(2 / 68)$ \\
\hline & & Within $0.5^{\circ} \mathrm{C}$ & $99.9 \%(0 / 1)$ & $98.2 \%(0 / 21)$ \\
\hline & & Within $1.0^{\circ}$ & $99.9 \%(0 / 1)$ & $99.7 \%(0 / 3)$ \\
\hline
\end{tabular}


Figure 1. Schematic showing the relationship between Niche Mapper's microclimate and animal submodels as well as the inputs required by the respective submodel for Niche Mapper's heat balance calculations.

Figure 2. Example plots of NM's hourly predicted body temperatures $\left(\mathrm{T}_{\mathrm{b}}\right)$ and hourly observed female $\mathrm{T}_{\mathrm{b}}$ for a winter month (a; August 2014) and a summer month (b; December 2014). The maximum predicted $\mathrm{T}_{\mathrm{b}}$ is for a monkey active in sun for diurnal hours and a huddled monkey for nocturnal hours. The minimum predicted $\mathrm{T}_{\mathrm{b}}$ is for a monkey inactive in full shade for diurnal hours and for an uncurled monkey for nocturnal hours. The shaded gray area shows the range of observed $\mathrm{T}_{\mathrm{b}}$ for a given hour. Air temperatures are also shown for reference.

Figure 3. Plots of predicted vs. observed female body temperature $\left(\mathrm{T}_{\mathrm{b}}\right)$. For diurnal hours, the minimum NM $T_{b}$ is for a vervet inactive in the shade; the maximum $N M T_{b}$ is for a vervet active in the sun. An average of the maximum and minimum $T_{b}$ predictions, representing a mix of activity and inactivity, is also shown. For nocturnal hours, predictions are shown for different nighttime postures uncurled (minimum $\mathrm{T}_{\mathrm{b}}$ prediction), curled, and huddled (maximum $\mathrm{T}_{\mathrm{b}}$ prediction). The average prediction is the average of the maximum and minimum $T_{b}$ nocturnal predictions. The darker the color of the hexagon, the greater the number of hourly $\mathrm{T}_{\mathrm{b}}$ comparisons in that plot location. The dashed lines indicate the observed modal $\mathrm{T}_{\mathrm{b}} \mathrm{s}$ (lower overnight $T_{b}$ and higher daytime $T_{b}$ ) of the wild vervets; the solid line indicates a 1:1 relationship between observed and predicted $\mathrm{T}_{\mathrm{b}}$. Similar trends were observed for the male model.

Figure 4. The difference ( \pm S.D.) between observed and predicted female body temperatures $\left(T_{b}\right)$ for diurnal hours between 2012 and 2016. Data are broken down by hour (04:00-18:00) and season $($ summer $=$ December-February; winter = June-August; spring=March-May; fall=September-November). The minimum NM $T_{b}$ is for a vervet inactive in the shade; the maximum NM $\mathrm{T}_{b}$ is for a vervet active in the sun. The average prediction is the average of the maximum and minimum $\mathrm{T}_{\mathrm{b}}$ predictions, representing a mix of activity and inactivity. For 04:00 and 18:00 hours, daylight is only present for a summer month. Similar trends were observed for the male model (Fig. A.10).

Figure 5. The difference ( \pm S.D.) between observed and predicted body temperatures $\left(T_{b}\right)$ for nocturnal hours between 2012 and 2016. The data are broken down by hour (17:00-06:00) and season (summer = December-February; winter = June-August; spring/fall=March-May; September-November). The minimum NM $\mathrm{T}_{\mathrm{b}}$ is for a lone uncurled vervet; the maximum NM $\mathrm{T}_{\mathrm{b}}$ is for a huddled vervet. The average prediction is the average of the maximum and minimum $\mathrm{T}_{\mathrm{b}}$ predictions, representing a mix of postures. For 06:00, sunlight was absent only for a winter month. Similar trends were observed for the male model (Fig. A.11). 


\section{Figure 1.}

Microclimate Submodel User Inputs

- Daily $\mathrm{max} / \mathrm{min}$ :

- $2 \mathrm{~m}$ air temperature

- $2 \mathrm{~m}$ wind speed

- Cloud cover

- Relative humidity

- Overhead shade availabiity

- Surface reflectivity

- Subtrate thermal properties

- Slope, aspect, elevation

- Latitude/Longitude

- Days of year being modeled

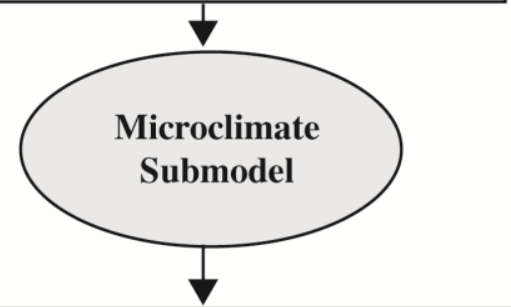

Microclimate Submodel Outputs

- Hourly air temperatures, wind speeds, relative humidities

- At $2 \mathrm{~m}$ and animal height

- In minimum and maximum available shade

- Hourly cloud cover

- Hourly surface temperatures

- In minimum and maximum available shade

- Hourly solar radiation

- Hourly sky temperatures

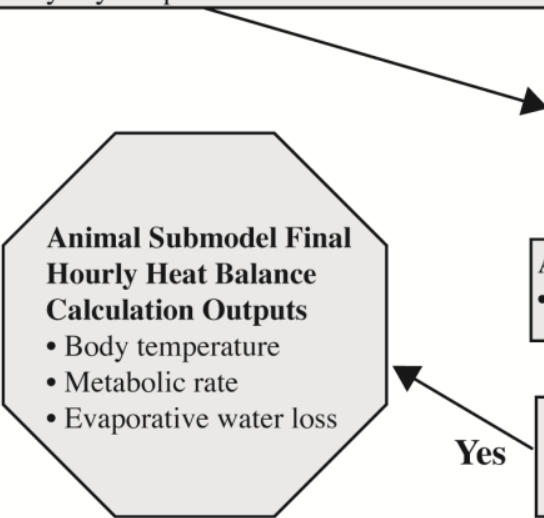

\section{Animal Submodel User Inputs}

- Morphological

- Body mass

- Body part shape and dimensions

- Pelage properties

- Resting posture (stretched, curled, huddled)

- Physiological

- Starting, minimum, maximum body temperature

- Starting, minimum, maximum flesh thermal conductivity

- Resting metabolic rate*

- Active metabolic rate multiplier (x resting metabolic rate)

- Starting, maximum \% surface area wet

- Starting, minimum oxygen extration efficiency (\%)

- Ability to pant (Y/N)

- Ability to piloerect pelage (Y/N)

- Behavioral

- Time of day active (diurnal, crepuscular, nocturnal hours)

- Live on land or in water

- Ability to swim when hot (Y/N)

- Ability to climb trees when hot (Y/N)

- Ability to seek shade when hot or cold (Y/N)

- Ability to burrow when hot or cold (Y/N)

- Ability to huddle when cold (Y/N)

- Ability to assume a curled posture when cold (Y/N)

* Users can optionally enter a resting metabolic rate. If no data are available, the model's default resting metabolic rate is a generic mammalian regression relationship between animal mass and resting metabolic rate.

Calculated metabolic rate within error tolerance of target metabolic rate or thermoregulatory options exhausted?

\section{Themoregulation}

- Behavioral (as allowed):

- Change microclimate conditions by seeking shade, climbing, swimming, or burrowing

- Change posture

- Physiological (as allowed):

- Adjust flesh thermal conductivity

- Adjust body temperature

- Increase \% surface area wet (if hot)

- Piloerect pelage (if cold) 


\section{$986 \quad$ Figure 2.}

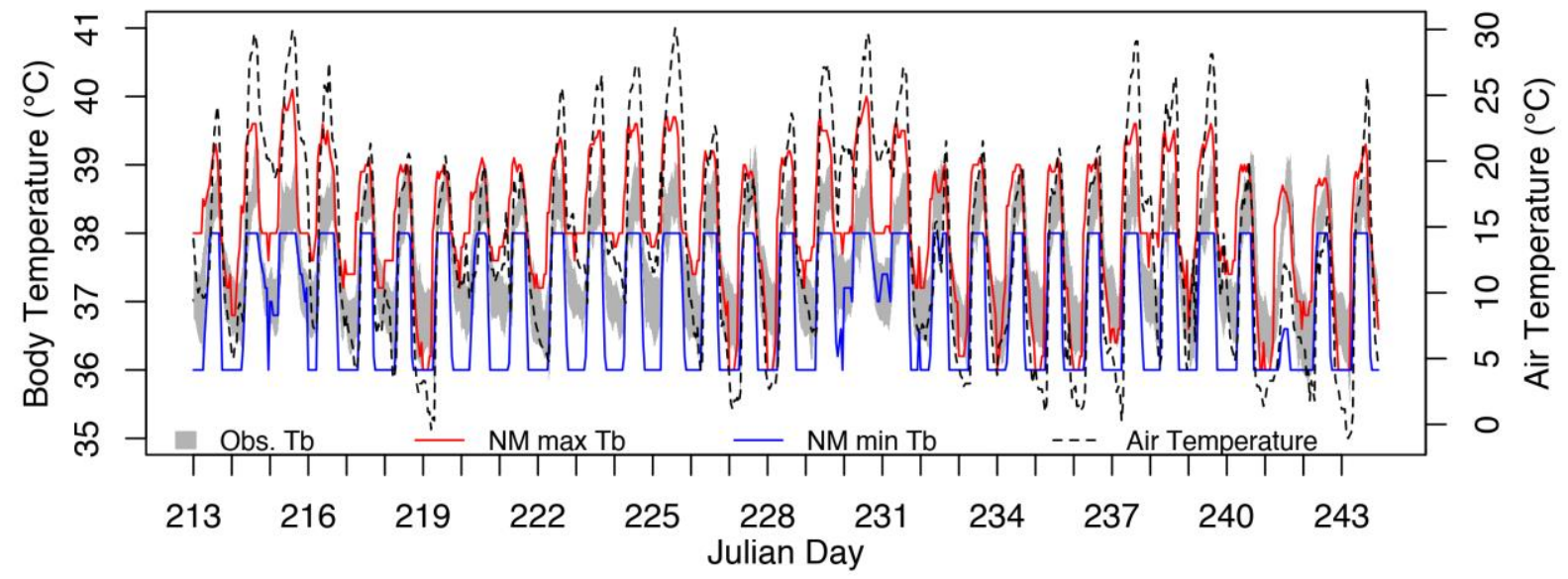

(a)

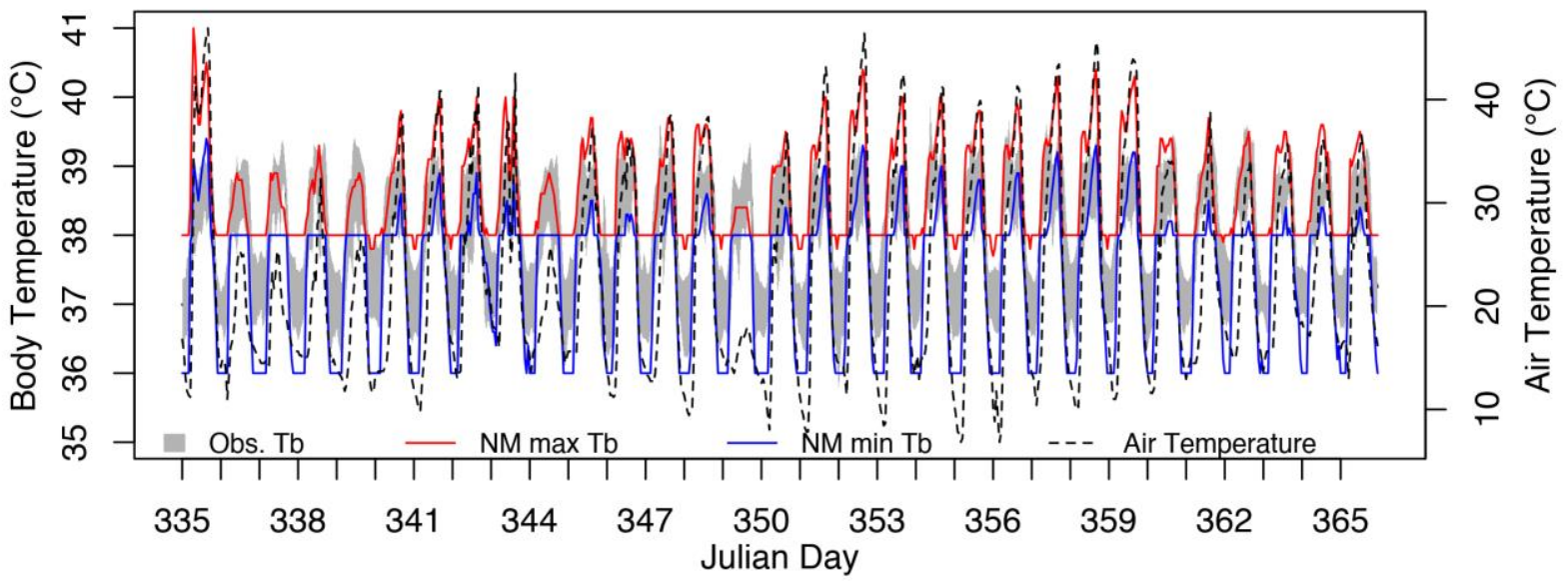

(b) 
Figure 3.
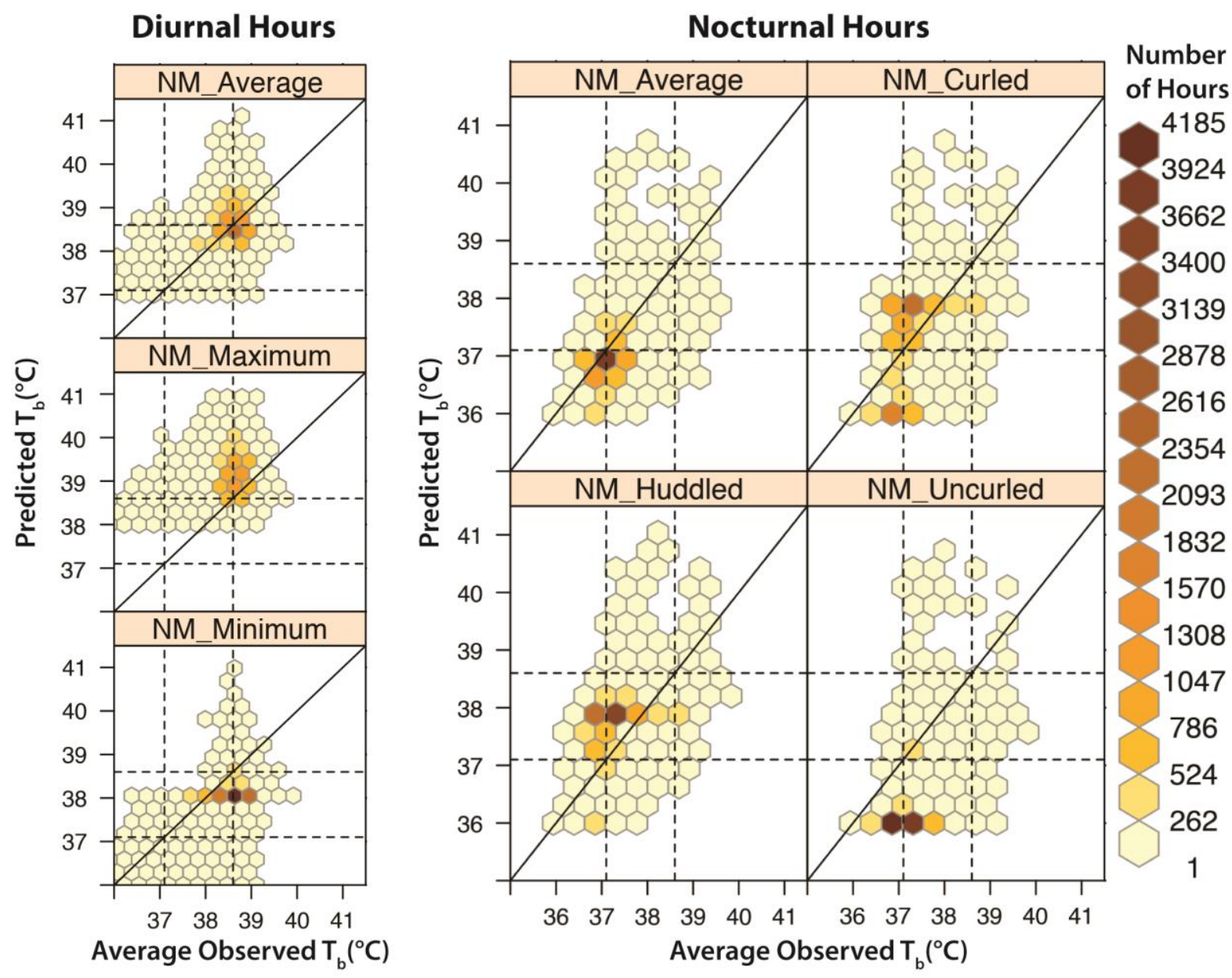


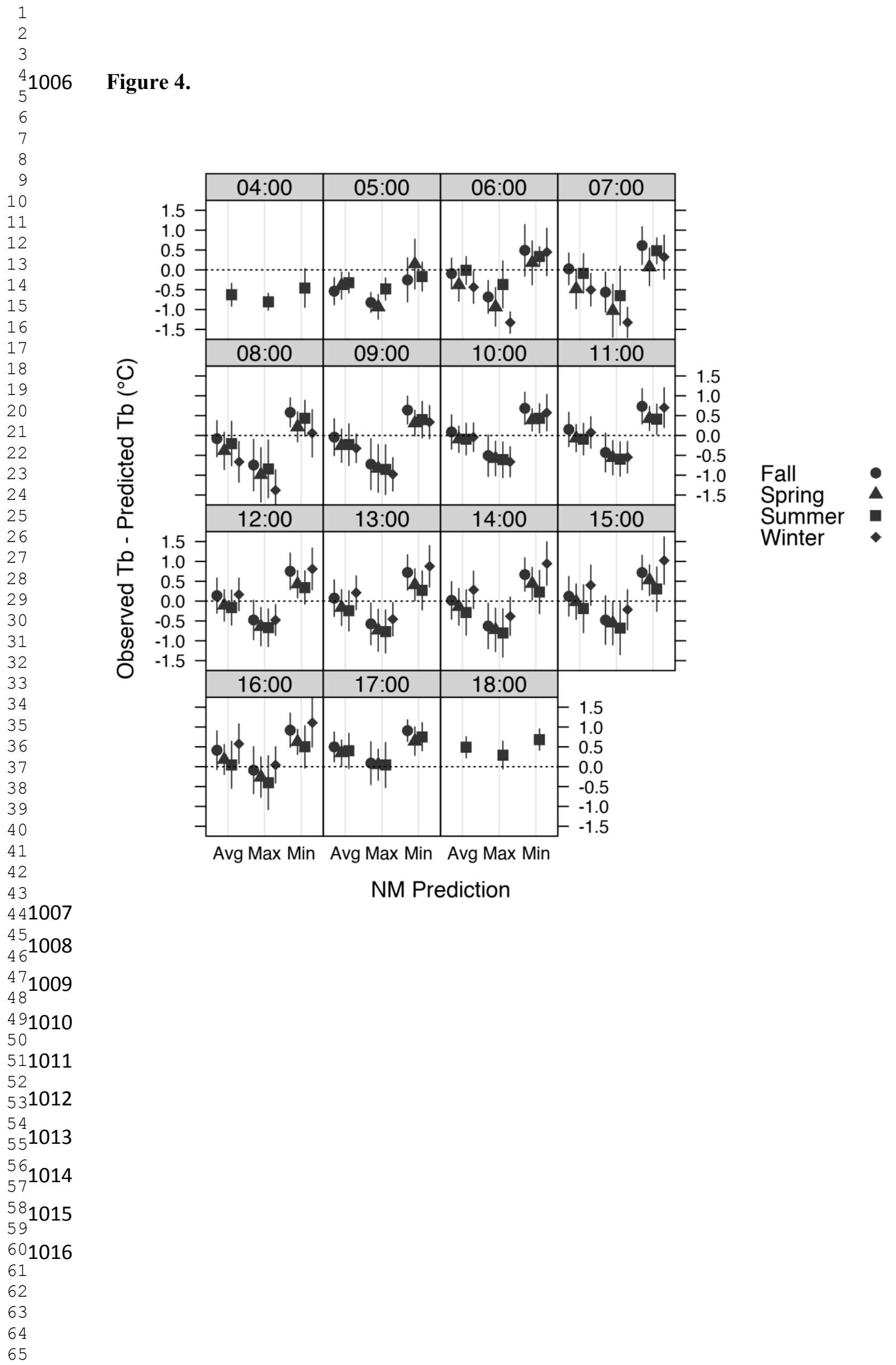




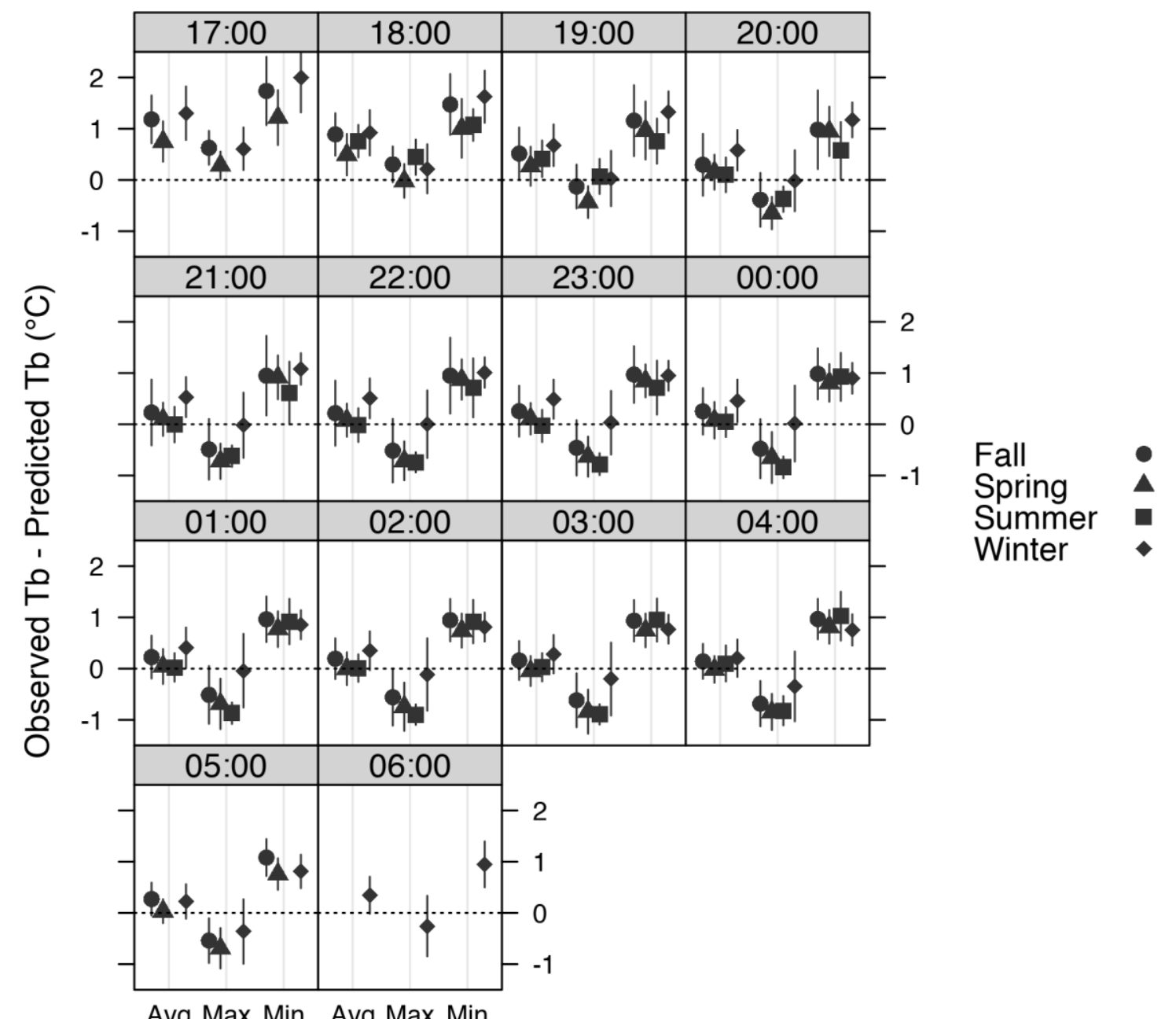

NM Prediction 


\section{CRediT AUTHOR STATEMENTS}

Paul D. Mathewson: Conceptualization, Methodology, Formal analysis, Software, Investigation, Data curation, Writing-Original Draft, Visualization Warren P. Porter: Conceptualization, Methodology, Supervision, Resources, Writing-Review \& Editing Louise

Barrett: Methodology, Investigation, Resources, Writing-Review \& Editing, Supervision, Funding acquisition Andrea Fuller: Methodology, Investigation, Resources, Writing-Review \& Editing, Supervision, Funding acquisition S. Peter Henzi: Methodology, Investigation, WritingReview \& Editing Supervision, Funding acquisition Robyn S. Hetem: Methodology, Investigation, Resources, Writing-Review \& Editing Supervision, Funding acquisition Christopher Young: Investigation, Data Curation, Writing-Review \& Editing Richard McFarland: Conceptualization, Methodology, Investigation, Resources, Writing-Review \& Editing, Supervision, Funding acquisition 


(1)

(Supplementar Materiat

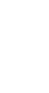

\author{
Click here to access/download \\ Supplementary Material \\ Appendix_R1_final.docx

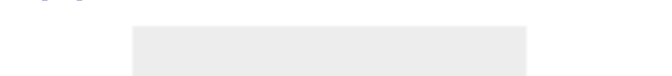

(n)

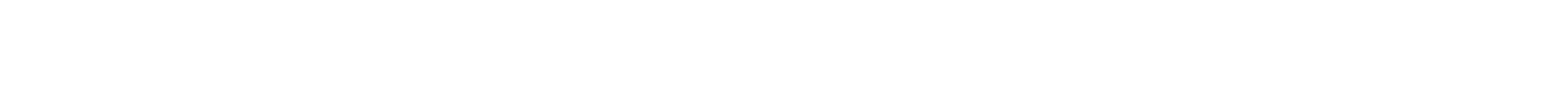

(1)

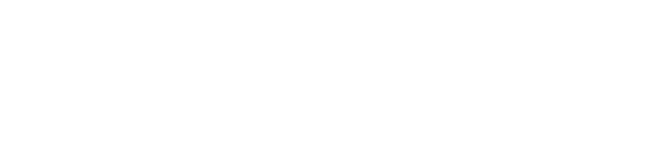

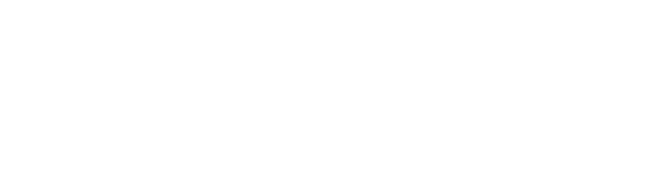
(1) (1) (1) (1)

(1)

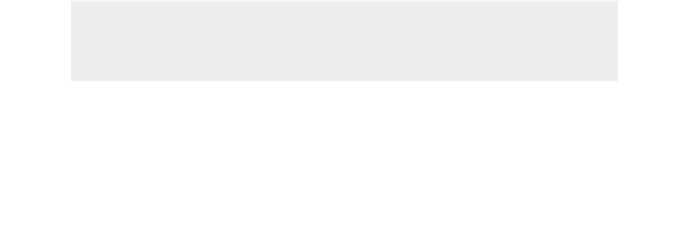
列

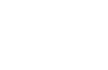
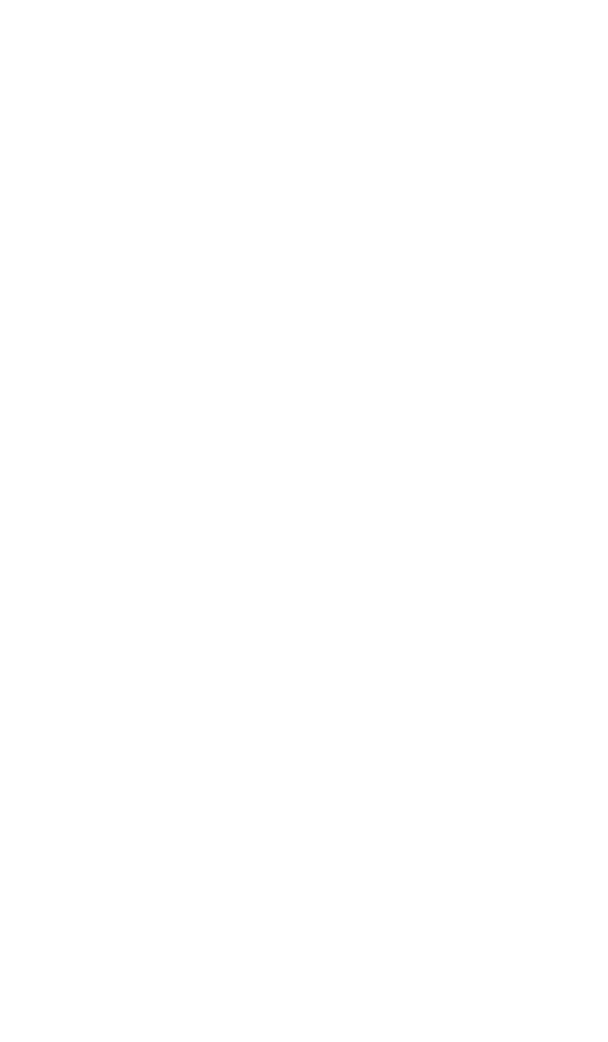

(1) (1) (1) (1) . . 